\title{
Power-to-methanol: The role of process flexi- bility in the integration of variable renewable energy into chemical production
}

Chao Chen ${ }^{1}$, Aidong Yang ${ }^{1, *}$

${ }^{1}$ Department of Engineering Science, University of Oxford, Parks Road, Oxford OX1 3PJ, UK

${ }^{*}$ Corresponding author. Email: aidong.yang@eng.ox.ac.uk

Key words: process flexibility, methanol, renewable source intermittency, energy storage, conceptual design, model-based optimisation

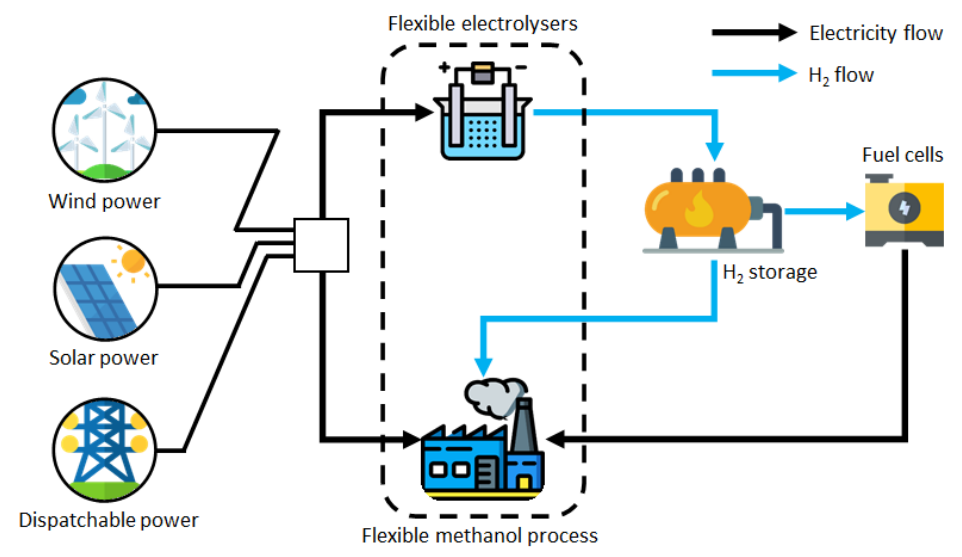

\section{Abstract}

2 Chemical process electrification and renewable energy integration facilitate one 3 another along the pathway towards a greener industry. However, integrating 4 intermittent and variable renewable power into large-scale chemical processes, 5 which conventionally are preferred to operate at a steady-state with a constant 6 load, could lead to prohibitive costs if intermittency is addressed solely by 
energy storage. Here, we consider the concept of a flexible chemical process which can operate with a variable load throughout the year while meeting a specified annual production target. Using methanol production via carbon dioxide hydrogenation as a case study and by means of process conceptual design and optimisation, we investigate how the over-sizing of flexible process units and the introduction of intermediate storage in the chemical process offer the possibility to improve the overall performance of systems. The impact of the characteristics of renewable power is also explored by performing the analysis using meteorological data from two locations dominated respectively by wind and solar energy. This study shows clear potential benefits of process flexibility when the renewable energy supply is highly variable and is to achieve a high level of penetration. For a $100 \%$ renewable production, the introduction of flexibility reduces the levelised cost of methanol by approximately 21 and $34 \%$ for the two case study locations, respectively. The cost attribution reveals further insights into the origin of the economic advantages through examining the comparative costs of chemical production, energy generation, intermediate product storage and renewable energy storage. The learning from this work suggests that incorporating process flexibility through a holistically optimised design of energy storage and chemical production has the potential to offer an economically viable route to large-scale green chemical production through renewables-enabled electrification.

\section{Introduction}

The transition in the major energy sources to fuel the economy has occurred several times in history: from animal power and biomass through coal to oil and gas, now moving towards a range of renewables in their modern 
versions. For chemical industry, the ongoing energy transition potentially impacts on both its energy supply and feedstock. In particular, electrification of chemical production with renewables presents a great opportunity to drive the industry away from its unsustainable dependence on fossil fuels [1], which can be viewed as part of the widespread electrification in the economy to harness the synergies from coordinating the deployment of renewable power generation and the demand sectors [2]. It is envisioned that the transition of electrification and the use of renewable power, which promote each other, will lead to a "green" industry and become the key in meeting environmental targets [3].

\subsection{What is the challenge}

Although chemical industry electrification with renewable energy is promising, a high penetration of variable renewable sources in power systems poses significant operational challenges. Unlike other energy uses where demand side flexibility could be brought in to address the variability and intermittency of renewable energy [4], conventional chemical processes typically operate continuously at a steady-state, imposing a constant (and rigid) energy demand. Such a rigid demand on the other hand cannot be adequately met by the management of the generation side for mitigating renewable energy variability, such as diversifying renewable sources [5] and excess renewable energy provision [6]. To date, the limitation in renewable chemical production is largely addressed by energy storage, particularly in the form of compressed hydrogen $\left(\mathrm{H}_{2}\right)$ to level renewable power output, which has been demonstrated in both "green" ammonia [7] and methanol production [8]. Although $\mathrm{H}_{2}$ plays a critical role in renewable energy storage, its technical barriers [9] are significant - expensive storage tanks, high pressure storage and potential 
safety issues - making it less favourable for long-term storage and large-scale applications. In light of this, it is urgent to explore new concept and techniques specifically for chemical production powered by renewables.

\subsection{Why flexibility}

To tackle the burden of energy storage for integrating renewables into chemical industry, a separate line of thinking is on tapping into the flexibility in chemical processes, which has not been much emphasised in conventional steady-state production. A flexible chemical process allows the demand side to adjust according to the variable pattern of renewable energy, thus incorporating demand side management to balance power generation and end-use load. In fact, the reason why a $\mathrm{H}_{2}$-based energy storage system (ESS) has been widely used in balancing renewable power generation [10] can be attributed to its flexible operation, i.e., water electrolysis can generally run at flexible loads to accommodate the variability of renewable sources. Unlike the electrolysers, chemical synthesis reactors and other complex chemical processes require careful management in order to accommodate the capacity of being flexible.

Several recent studies have recognised the importance of the operational flexibility of chemical reactors, with the anticipation of increasing integration with renewable resources [11]. It should be pointed out that disparity exists in the level of flexibility rendered by different chemical process units. For example, a wide range of feasible load was reported of a fixed-bed methanation reactor with the lower and upper bounds of the superficial velocity being 10 times apart [12]. In contrast, cryogenic distillation for air separation was considered to be much less flexible, with the feasible load being no lower than $60 \%$ of its full capacity [13]. A chemical plant typically comprises multiple types of units for distinct tasks such as chemical conversion and separation; 
the difference in their flexibility makes it very challenging to vary the load of the chemical plant as a whole. Instead, these units may have to operate at different load levels within the limits they can individually accommodate. This would necessitate storage of intermediate products (exchanged between upstream and downstream processing) and possibly energy (such as heat due to energy integration between process units) to align the operation of multiple units. Furthermore, the use of such storage would need to be optimally coordinated with the use of the renewable energy storage, hence the need for the optimal coordination between flexible energy generation and flexible chemical production. This complexity has not been understood in existing power-to-chemical studies that consider some degree of process flexibility [14] (typically with the involved chemical reactor). Despite the added complexity, this strategy may lead to an enhanced economic feasibility of renewables powered chemical production, provided that the benefits of the flexibilityenabling storage introduced within the chemical plant outweighs its cost. Should such a system be proven to be more advantageous than integrating variable renewable energy into chemical production that operates at a constant load mediated solely by (expensive) energy storage, it could become one of the new paradigms for chemical process design in the era of renewables.

\subsection{Why methanol}

Renewable methanol as a commodity [15] or a vector to synthetic hydrocarbons [16] has received increasing attention in the recent literature, often with an emphasis on carbon dioxide $\left(\mathrm{CO}_{2}\right)$ valorisation [17]. In this work, we have undertaken a detailed model-based evaluation of the novel strategy with power-to-methanol production. We have chosen methanol for a detailed case study not only because of its own importance as a platform chemical that 
can be further converted to a wide range of other chemicals and materials, but also because it presents a good range of challenges in terms of exploiting process flexibility to cope with the variable supply of renewables: (1) it involves reaction and separation process sections which are both fairly complex; (2) its use of $\mathrm{CO}_{2}$ as a feed and its production of crude methanol as an intermediate product introduce the potential need for storage of both gaseous and liquid materials; (3) the process also offers an opportunity to investigate the implication of process flexibility on heat integration across multiple units which is commonly encountered in a sophisticated modern chemical plant. These features are representative of future renewables-powered productions of carbon-based chemicals and fuels.

Herein, we consider a methanol plant which acquires $\mathrm{CO}_{2}$ by carbon capture from a point source and $\mathrm{H}_{2}$ from electrolysis, with a methanol synthesis loop centred on a catalytic reactor and a distillation-based step for product purification. The plant investigated in this work is fully electrified, supplied by a wind and/or solar power generation facility which is optionally complemented by dispatchable power. In this system, the variability of renewable energy supply is tackled by a combination of a $\mathrm{H}_{2}$-based ESS and process flexibility enabled by the storage of process materials and energy (heat). A detailed optimisation model was constructed to establish the economically best design of the combination, in terms of the sizes of system components, power mix, and the arrangement of energy and material flows between different system units. The optimal design was contrasted with the non-flexible conventional production under different settings of the renewables' profile, the price of dispatchable power and the level of attainable process flexibility. In this analysis, both the cost for methanol production and level of renewables penetration (as an environmental consideration) were assessed. 
To our knowledge, this is the first detailed modelling work on power-tomethanol to investigate holistically the interplay between $\mathrm{H}_{2}$ and methanol processes and the complementary roles of multiple types of storage within the whole system. As a new effort in the emerging area of combining process electrification with $\mathrm{CO}_{2}$ utilisation, the intention of this work is to reveal the key mechanisms by which process flexibility can potentially improve the economic and environmental performances of chemical production powered by variable renewable sources.

\section{Methods}

\subsection{Concept overview}

A fully electrified methanol process (adopted from our previous study [18]) with an annual production rate of approximately 400,000 tonnes was considered for two geographical locations, namely Norderney (Germany) and Kramer Junction (US), which have excellent wind and solar power sources, respectively, with profiles quantified by year-round hourly data. As shown in Figure 1, the system that converts power (from both variable renewables and the dispatchable backup) to methanol consists of four production subsystems, namely electrolysis (ELY) for producing $\mathrm{H}_{2}$, carbon capture (CC) for supplying $\mathrm{CO}_{2}$, methanol synthesis $(\mathrm{SYN})$ for producing raw methanol and distillation (DT) for product purification. The disparity in the operational flexibility between these subsystems was modelled by adopting a constant load for the carbon capture subsystem (which is supposed to process a flue gas stream from a constant external supply) and the distillation subsystem (with known limited flexibility), while the load of electrolysers and methanol synthesis is flexible and each can vary within a broad range with an excess 
capacity (compared with that defined by the stoichiometric requirement). When the renewable power is in surplus, excess $\mathrm{H}_{2}$ (via electrolysis) and/or raw methanol (via synthetic reactor) can be produced and stored in respective storage subsystems (i.e., STh and STm) for subsequent consumption when the renewable power is in deficit. When the power deficit is too large, the stored $\mathrm{H}_{2}$ can additionally be fed to the fuel cells to sustain a minimum level of operation of the methanol plant. The backup dispatchable power is a fail-safe measure to ensure a sustainable production. In addition, the $\mathrm{CO}_{2}$ storage subsystem (STc) is required to handle the load mismatch between carbon capture and methanol synthesis. Also placed between these two subsystems is a heat storage unit (STq); this is to facilitate the heat integration between the exothermic $\mathrm{CO}_{2}$ hydrogenation reactor (as a heat source) and the regeneration column for amine-based $\mathrm{CO}_{2}$ capture (as a heat sink), which may operate at different load levels.

The energy and material flow data of the system shown in Figure 1 were generated from simulations using Aspen Plus (Supplementary Tables 6, 9 and 12). Building on the mass and energy balance data and subject to further physical and operational constraints, an optimisation model was used to determine the economically most superior design, which defines the mix of power supply (wind, solar and dispatchable), the size of each flexible subsystem (electrolysis and methanol synthesis) and the size of each storage (hence the most economic combination of $\mathrm{H}_{2}$ and other in-process storage capacities), as well as the optimal hourly scheduling of material and energy flows between various components of the system. 


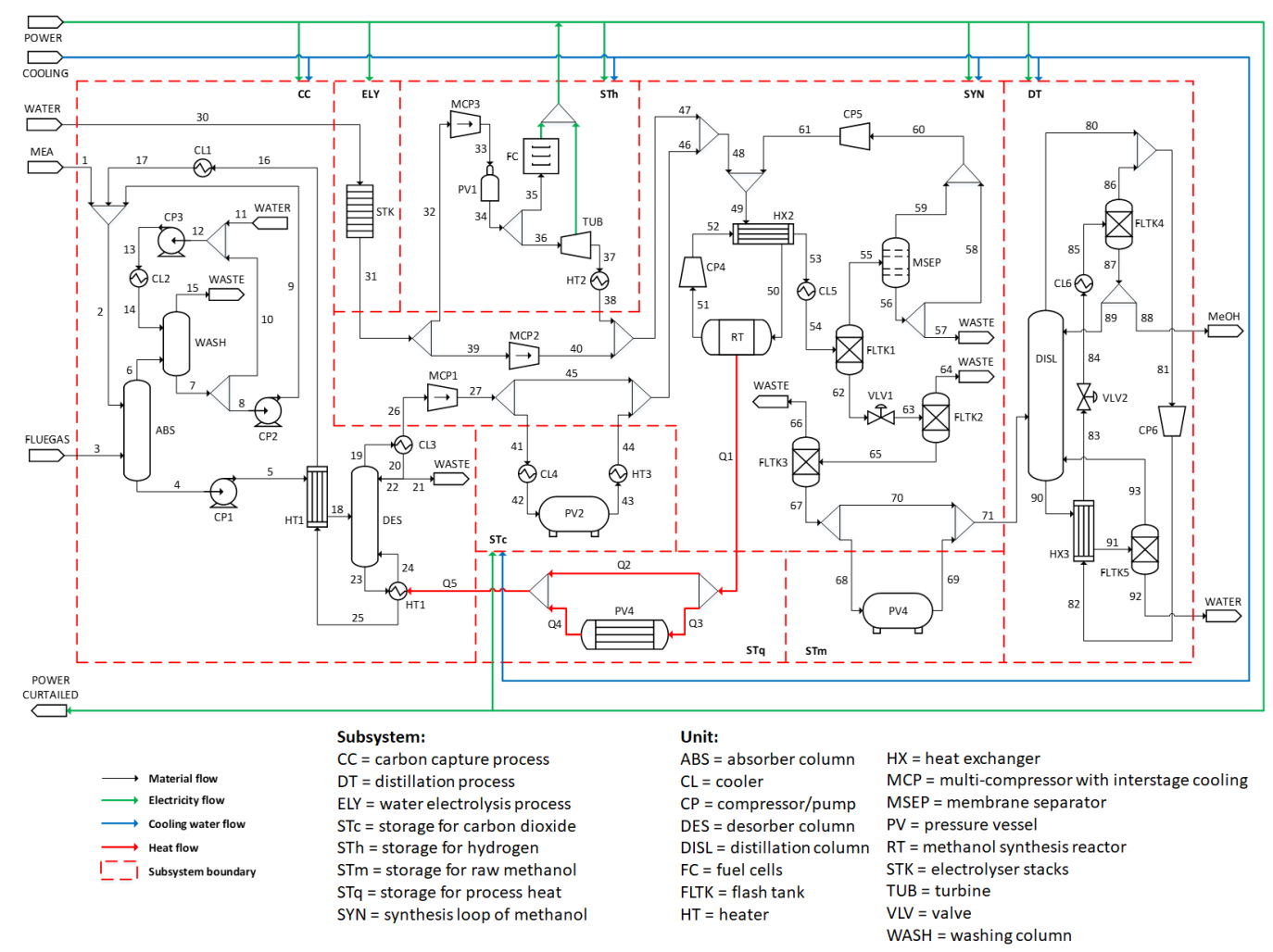

Figure 1. Flowsheet of the electrified methanol production and its subsystems.

\section{$2.2 \quad$ Process modelling}

\subsubsection{Carbon capture process}

The simulation of the carbon capture process is adopted from an example of the rate-based monoethanolamine (MEA) absorption process [19]. The equation-of-state models are inherited from the original design, which employs an electrolyte NRTL activity coefficient model for the liquid phase and the Redlich-Kwong physical property model for the vapour phase. The process flow diagram is given in Supplementary Figure 5.

The captured $\mathrm{CO}_{2}$ is from the flue gas of a point source, which has a composition shown in Supplementary Table 7. The flue gas is first fed to the absorber, which is then scrubbed by the MEA solvent $\left(\mathrm{CO}_{2}\right.$ lean $)$. The 
scrubbed gas contains a small fraction of MEA. Thus, it undergoes a two-stage washing column to minimise the loss of MEA before venting to the ambient. The liquid stream from the washing column splits into two recycle streams, which are fed to the washing column and the absorber, respectively. The $\mathrm{CO}_{2}$ rich solvent from the absorber is fed to the desorber to recover $\mathrm{CO}_{2}$ (top product) and MEA (bottom product). The lean solvent from the desorber then goes through a heat exchanger to recover the heat before being recycled back to the absorber. The desorber is modelled as a reactive distillation column with a partial condenser operating at $18.0^{\circ} \mathrm{C}$ and a reboiler operating at $119.3^{\circ} \mathrm{C}$. The condenser is designed with a reflux ratio of 0.58 , while the boilup ratio of the reboiler is set to 0.06 . Both the absorber and the desorber are modelled with a RADFRAC unit using a rate-based model. The captured $\mathrm{CO}_{2}$ product has a purity of $99.4 \mathrm{wt} \%$ with small fractions of water and nitrogen. For simplicity, the impurities are neglected when the $\mathrm{CO}_{2}$ stream is fed to the downstream process. The stream properties are summarised in Supplementary Table 6 .

The chemistry of the absorption and the regeneration consists of 5 instantaneous reactions (Reactions 1-5) and 4 finite rate reactions (Reactions 6-9), 
which are shown as follows:

$$
\begin{aligned}
& \mathrm{MEAH}^{+}+\mathrm{H}_{2} \mathrm{O} \longleftrightarrow \mathrm{MEA}+\mathrm{H}_{3} \mathrm{O}^{+} \\
& \mathrm{MEACOO}^{-}+\mathrm{H}_{2} \mathrm{O} \longleftrightarrow \mathrm{MEA}+\mathrm{HCO}_{3}^{-} \\
& 2 \mathrm{H}_{2} \mathrm{O} \longleftrightarrow \mathrm{H}_{3} \mathrm{O}^{+}+\mathrm{OH}^{-} \\
& \mathrm{CO}_{2}+2 \mathrm{H}_{2} \mathrm{O} \longleftrightarrow \mathrm{HCO}_{3}^{-}+\mathrm{H}_{3} \mathrm{O}^{+} \\
& \mathrm{HCO}_{3}^{-}+\mathrm{H}_{2} \mathrm{O} \longleftrightarrow \mathrm{CO}_{3}^{2-}+\mathrm{H}_{3} \mathrm{O}^{+} \\
& \mathrm{CO}_{2}+\mathrm{OH}^{-} \longrightarrow \mathrm{HCO}_{3}^{-} \\
& \mathrm{HCO}_{3}^{-} \longrightarrow \mathrm{CO}_{2}+\mathrm{OH}^{-} \\
& \mathrm{MEA}+\mathrm{CO}_{2}+\mathrm{H}_{2} \mathrm{O} \longrightarrow \mathrm{MEACOO}^{-}+\mathrm{H}_{3} \mathrm{O}^{+} \\
& \mathrm{MEACOO}^{-}+\mathrm{H}_{3} \mathrm{O}^{+} \longrightarrow \mathrm{MEA}+\mathrm{CO}_{2}+\mathrm{H}_{2} \mathrm{O}
\end{aligned}
$$

${ }_{213}$ The equilibrium parameters for the instantaneous reactions are computed 214 from the Gibbs free energies, whereas the built-in power law equations are used for the rate-controlled reactions. The pre-exponential factor $(K)$ and activation energy $\left(E_{\mathrm{a}}\right)$ of Reactions 6-9 are tabulated in Supplementary Table 8.

The condenser is operated at a temperature lower than the cooling water due to product specification requirement. Thus, it is assumed that the vapour at the top of the desorber is first cooled to $40{ }^{\circ} \mathrm{C}$ by cooling water and followed by refrigeration to chill further to $18^{\circ} \mathrm{C}$. The mechanical power $(\dot{W})$ required to run the refrigerator is calculated by

$$
\dot{W}=\dot{Q}\left(\frac{T^{\mathrm{H}}}{T^{\mathrm{L}}}-1\right) \frac{1}{\eta_{\mathrm{refg}}}
$$

${ }^{223}$ where $\dot{Q}$ is the rate of heat extracted from the process stream, $\eta_{\text {refg }}$ is the 
refrigeration efficiency taken as $50 \%$ and $T^{\mathrm{H}}(308.15 \mathrm{~K})$ and $T^{\mathrm{L}}(281.15 \mathrm{~K})$ denote the temperature of heat source and sink, respectively.

\subsubsection{Carbon dioxide hydrogenation process}

The $\mathrm{CO}_{2}$ hydrogenation process is the key subsystem that allows a flexible operation; in particular, the size of the catalytic reactor is designed with excess capacity and variable load range to balance the renewable power fluctuation. The reactants from the upstream are first mixed with a recycle stream and pre-heated through a heat exchanger before feeding to the reactor. The chemistry of the reactor is adopted from Ref. [20], which consists of the hydrogenation of $\mathrm{CO}_{2}$ (Reaction 11) and $\mathrm{CO}$ (Reaction 12), and the reverse water-gas-shift reaction (Reaction 13). These reactions are list as follows:

$$
\begin{aligned}
& \mathrm{CO}_{2}+3 \mathrm{H}_{2} \longleftrightarrow \mathrm{CH}_{3} \mathrm{OH}+\mathrm{H}_{2} \mathrm{O} \\
& \mathrm{CO}+2 \mathrm{H}_{2} \longleftrightarrow \mathrm{CH}_{3} \mathrm{OH} \\
& \mathrm{CO}_{2}+\mathrm{H}_{2} \longleftrightarrow \mathrm{CO}+\mathrm{H}_{2} \mathrm{O}
\end{aligned}
$$

The process flow diagram is shown in Supplementary Figure 6. The process parameters such as operation temperature, pressure and split and recycle ratios are inherited from the work of Perez-Fortes et al. [21]. The catalytic reactor, operated at $255^{\circ} \mathrm{C}$ and 71 bar, is modelled with an isothermal RPLUG unit in Aspen Plus. The kinetic model is adopted from the work of Bussche and Froment [22] with adjusted parameters [23], which is based on a commercial $\mathrm{Cu} / \mathrm{ZnO} / \mathrm{Al}_{2} \mathrm{O}_{3}$ catalyst. The NRTL-RK equation-of-state is employed to calculate the thermodynamic properties in methanol synthesis due to its capability to predict non-ideal behaviours [24]. 
The heat of the reactor effluent is recovered by heating the reactor inlet via mechanical vapour recompression (MVR) in order to maximise the heat recovery within the subsystem. The product stream then flows through the first flash tank to separate most of the vapour products at high pressure (70 bar) but low temperature $\left(40^{\circ} \mathrm{C}\right)$. The vapour stream undergoes a polymeric membrane separator to enrich $\mathrm{H}_{2}$, which is modelled with a SEP unit. The performance of the membrane separator is manually entered in Aspen Plus using the data obtained from Ref. [25]. A fraction of the gas stream after the membrane separator is purged, while the rest is recycled back along with the enriched $\mathrm{H}_{2}$ stream. The liquid product undergoes a second flash tank at reduced pressure to minimise the gaseous impurities. Although the liquid stream only contains trace amounts of light components, a third flash tank is used to completely remove them in order to simplify the design of downstream purification. The flash tank is modelled with a SEP unit assuming perfect liquid-vapour separation. The liquid product is the raw methanol composed of water and methanol only, with methanol accounting for $63.4 \mathrm{wt} \%$. The process stream properties are summarised in Supplementary Table 9.

The reaction rate equations for $\mathrm{CO}_{2}$ hydrogenation are rearranged to suit the requirements of the LHHW (Langmuir-Hinshelwood-Hougen-Watson) kinetic model in Aspen Plus [20], as shown in Eqs. 14 and 15:

$$
\begin{aligned}
& r_{\mathrm{MeOH}}=\frac{k_{1} P_{\mathrm{CO}_{2}} P_{\mathrm{H}_{2}}-k_{6} P_{\mathrm{H}_{2} \mathrm{O}} P_{\mathrm{MeOH}} P_{\mathrm{H}_{2}}^{-2}}{\left(1+k_{2} P_{\mathrm{H}_{2} \mathrm{O}} P_{\mathrm{H}_{2}}^{-1}+k_{3} P_{\mathrm{H}_{2}}^{0.5}+k_{4} P_{\mathrm{H}_{2} \mathrm{O}}\right)^{3}} \quad\left[\frac{\mathrm{mol}}{\mathrm{kg}_{\mathrm{cat}} \mathrm{s}}\right] \\
& r_{\mathrm{RWGS}}=\frac{k_{5} P_{\mathrm{CO}_{2}}-k_{7} P_{\mathrm{H}_{2} \mathrm{O}} P_{\mathrm{CO}} P_{\mathrm{H}_{2}}^{-1}}{1+k_{2} P_{\mathrm{H}_{2} \mathrm{O}} P_{\mathrm{H}_{2}}^{-1}+k_{3} P_{\mathrm{H}_{2}}^{0.5}+k_{4} P_{\mathrm{H}_{2} \mathrm{O}}}\left[\frac{\mathrm{mol}}{\mathrm{kg}_{\mathrm{cat} \mathrm{s}} \mathrm{s}}\right]
\end{aligned}
$$

where $r_{\mathrm{MeOH}}$ and $r_{\mathrm{RWGS}}$ denote the reaction rate of methanol synthesis and reverse water-gas-shift, respectively. The kinetic constants are derived from 
the Arrhenius law, as shown in Eq. 16:

$$
k_{i}=K_{i} e^{-\frac{E_{\mathrm{a} i}}{R T}}
$$

where the pre-exponential constants and activation energy terms are rearranged in Eqs. 17-19. Their values are tabulated in Supplementary Table 10.

$$
\begin{aligned}
\ln k_{i} & =A_{i}+\frac{B_{i}}{T} \\
A_{i} & =\ln K_{i} \\
B_{i} & =-\frac{E_{\mathrm{a} i}}{R}
\end{aligned}
$$

\subsubsection{Methanol distillation process}

The distillation column is modelled with a RADFRAC unit aiming to produce a $99.8 \mathrm{wt} \%$ methanol product. The number of equilibrium stage is optimised to be 27 with a reflux ratio of 0.92 using design functions embedded in Aspen Plus. To maximise the heat integration within the subsystem, a design of a heat pump via MVR is proposed [26]. The MVR system upgrades the second stage vapour (heat source) to facilitate the energy transshipment to the reboiler (heat sink), thus simultaneously reducing the heating (in reboiler) and cooling (in condenser) duties. With an optimised flowrate of the working fluid, the MVR system leads to $100 \%$ reduction in heating (originally $33,423 \mathrm{~kW}$ ) and $94.8 \%$ reduction in cooling (originally $-29,111 \mathrm{~kW}$ ) at an additional mechanical work of $5,828 \mathrm{~kW}$. The process flowsheet of the MVR, key stream notations, process stream properties and results of optimisation are provided in Supplementary Figure 7, Table 11), Table 12 and Figure 8, 
respectively.

\subsubsection{Storage systems}

The storage subsystems are auxiliary units to balance the time-mismatched energy and material flows resulting from the optimal scheduling. They are essential for a variable load and an intermittent power supply. The storage for materials comprises (1) a $\mathrm{H}_{2}$-based system that includes compressors, fuel cells, a turbine and a heater and (2) liquefied $\mathrm{CO}_{2}$ and raw methanol storage tanks. The $\mathrm{H}_{2}$-based storage is a costly compressed gas system (172 bar) involving a complex network interplay and operation policy. In contrast, the $\mathrm{CO}_{2}$ and raw methanol storage systems are rather simple: they are stored in pressure vessels under moderate conditions with straightforward connections with the rest of the system. While raw methanol is stored at room conditions, $\mathrm{CO}_{2}$ is stored at 71 bar (a required pressure for downstream processes) and $29.3^{\circ} \mathrm{C}$ (dew point of $\mathrm{CO}_{2}$ at the storage pressure). Note that the $\mathrm{CO}_{2}$ and raw methanol storage are conjugated due to material balance, i.e., for one unit of $\mathrm{CO}_{2}$ stored, a fixed ratio (governed by the reaction stoichiometry) of raw methanol will be withdrawn from its storage tank, and vice versa. The $\mathrm{H}_{2}$-based storage is not conjugated because $\mathrm{H}_{2}$ is used as both an energy vector (to fuel cells) and a material buffer (to downstream processes).

The heuristic principle in the conceptual process design is to arrange heat integration primarily within each subsystem (e.g., the MVR-based design in distillation) and to minimise integration across different subsystems. This is to avoid (1) expensive cross-system heat storage and (2) reduced operability resulting from a complex heat integration network. However, there is a pair of heat sink and source across two subsystems that has shown viable economical integration from an initial assessment. This cross-system heat 
This part of the optimisation model concerns the energy and material flows between all subsystems and the corresponding storage units. It excludes predefined operation policy but provides the physical bounds to the optimiser. Since the analysis is based on a fully electrified chemical plant, the energy 
flow mainly comprises the electricity and cooling water, with one exception in the SYN subsystem where excess heat from the catalytic reactor is fed to the reboiler in CC subsystem. The overall energy balances for electricity and cooling duty are modelled respectively by

$$
\begin{aligned}
& 0=P_{\mathrm{in}}(t)-\sum_{k} x_{\mathrm{el}}^{k}-P_{\mathrm{out}}(t) \\
& 0=E_{\mathrm{cw}}-\sum_{k} \sum_{t=1}^{N} x_{\mathrm{cw}}^{k}(t)
\end{aligned}
$$

where $P_{\text {in }}$ denotes all power (including renewable and dispatchable power) provided to the whole system, $P_{\text {out }}$ denotes the curtailed power, $E_{\mathrm{cw}}$ denotes the total cooling duty required by the whole system, $x_{j}^{k}$ is the consumption of $j$ utility in $k$ subsystem and $N$ is the total operational hours in a year, which is assumed to be $8,760 \mathrm{~h}$. Both electricity and cooling duty are measured in kilowatt. The electricity and cooling water flows to the individual subsystems are quantified by Eqs. 23-28:

$$
\begin{aligned}
& x_{\mathrm{el}}^{\mathrm{SYN}}(t)=a_{1}^{\mathrm{SYN}}+a_{2}^{\mathrm{SYN}} F_{39}(t)+a_{3}^{\mathrm{SYN}} \dot{\xi}(t) \\
& x_{\mathrm{el}}^{\mathrm{STh}}(t)=a_{1}^{\mathrm{STh}} F_{32}(t)+a_{2}^{\mathrm{STh}} F_{36}(t)-a_{3}^{\mathrm{STh}} F_{35}(t)-a_{4}^{\mathrm{STh}} F_{36}(t) \\
& x_{\mathrm{el}}^{\mathrm{STc}}(t)=a_{1}^{\mathrm{STc}} F_{44}(t) \\
& x_{\mathrm{cw}}^{\mathrm{SYN}}(t)=a_{4}^{\mathrm{SYN}}+a_{5}^{\mathrm{SYN}} F_{39}(t)+a_{6}^{\mathrm{SYN}} \dot{\xi}(t) \\
& x_{\mathrm{cw}}^{\mathrm{STh}}(t)=a_{5}^{\mathrm{STh}} F_{32}(t) \\
& x_{\mathrm{cw}}^{\mathrm{STc}}(t)=a_{2}^{\mathrm{STc}} F_{41}(t)
\end{aligned}
$$

where $F$ denotes the flowrate of a process stream, $\dot{\xi}$ the hourly extent of reaction and $a^{k}$ the constant process coefficient for $k$ subsystem (obtained from Aspen Plus simulations). 
The electricity consumption of ELY subsystem $\left(x_{\mathrm{el}}^{\mathrm{ELY}}\right)$ and the extent of reaction (i.e., the methanol synthesis rate) of SYN subsystem $(\dot{\xi})$ are of special interest because they are governed by the load fraction and the maximum capacity of the corresponding units. Therefore, the two variables are modelled explicitly using Eqs. 29 and 30 with additional decision variables:

$$
\begin{aligned}
x_{\mathrm{el}}^{\mathrm{ELY}}(t) & =\phi(t) x_{\mathrm{el}, \max }^{\mathrm{ELY}} \\
\dot{\xi}(t) & =\phi(t) \dot{\xi}_{\max }
\end{aligned}
$$

where $x_{\mathrm{el}, \text { max }}^{\mathrm{ELY}}$ denotes the maximum capacity of the electrolysers measured in rated power and $\dot{\xi}_{\max }$ denotes the maximum size of the catalytic reactor measured in terms of extent of reaction.

Since the subsystem of DT is non-flexible and has no interactions with other subsystems except the feed stream, $x_{j}^{\mathrm{DT}}$ becomes a constant for both electricity and cooling duty. Although the subsystem of CC is also non-flexible, its reboiler is partially powered by the heat from SYN subsystem. Therefore, the electricity consumption of CC subsystem is calculated by

$$
x_{\mathrm{el}}^{\mathrm{CC}}(t)=x_{\mathrm{el}, 0}^{\mathrm{CC}}-\dot{Q}_{5}(t)
$$

where $x_{\mathrm{el}, 0}^{\mathrm{CC}}$ denotes the constant electricity consumption when process heat is not integrated and $\dot{Q}_{5}$ denotes the process heat from SYN via heat storage subsystem (STq). This equation also implicitly takes the physical bound into account, i.e., the recovered heat $\left(\dot{Q}_{5}\right)$ would never exceed the load requirement of the reboiler for all $t$. The heat generated from the catalytic reactor is calculated by

$$
\dot{Q}_{1}(t)=b_{\mathrm{q}} \dot{\xi}(t)
$$


where $b_{\mathrm{q}}$ is a constant parameter denoting the specific heat output. Similarly, this equation also implicitly suggests that all heat from the catalytic reactor has to be integrated. This is justified by the cheaper heating from STq subsystem in comparison with electrical heating.

The material flows include the feed water to the electrolysers (Eq. 33), the generated $\mathrm{H}_{2}$ from the electrolysers (Eq. 34), the $\mathrm{H}_{2}$ fed to the methanol synthesis (Eq. 35), the $\mathrm{CO}_{2}$ fed to the methanol synthesis (Eq. 36), and the raw methanol generated from the synthesis subsystem (Eq. 37). These are quantified respectively by

$$
\begin{aligned}
& F_{30}(t)=\frac{M_{\mathrm{W}}\left(\mathrm{H}_{2} \mathrm{O}\right)}{M_{\mathrm{W}}\left(\mathrm{H}_{2}\right)} F_{31}(t) \\
& F_{31}(t)=\frac{x_{\mathrm{el}}^{\mathrm{ELY}}(t)}{e^{\mathrm{ELY}}(t)} \\
& F_{47}(t)=b_{\mathrm{h}} \xi(t) \\
& F_{46}(t)=b_{\mathrm{c}} F_{47}(t) \\
& F_{67}(t)=b_{\mathrm{m}} F_{47}(t)
\end{aligned}
$$

where $M_{\mathrm{W}}$ denotes molecular weight and $b$ denotes the constant parameters for species indicated by the subscripts.

There are four storage subsystems considered in this work, namely STh (for $\mathrm{H}_{2}$ ), STm (for raw methanol), STc (for $\mathrm{CO}_{2}$ ) and STq (for process heat), 
with their holdup quantified by

$$
\begin{aligned}
L^{\mathrm{STh}}(t) & =L^{\mathrm{STh}}(t-1)+F_{32}(t)-F_{34}(t) \\
L^{\mathrm{STc}}(t) & =L^{\mathrm{STc}}(t-1)+F_{41}(t)-F_{44}(t) \\
L^{\mathrm{STm}}(t) & =L^{\mathrm{STm}}(t-1)+F_{68}(t)-F_{69}(t) \\
L^{\mathrm{STq}}(t) & =L^{\mathrm{STq}}(t-1)+\dot{Q}_{3}(t)-\dot{Q}_{4}(t)
\end{aligned}
$$

where $L^{k}(t)$ denotes the storage level of $k$ subsystem at time $t$, which is updated by the previous storage level at time $t-1$ and the current material or energy flow at time $t$. The material and energy balances around the storage units are calculated by Eqs. 42-50:

$$
\begin{aligned}
& 0=F_{31}(t)-F_{32}(t)-F_{39}(t) \\
& 0=F_{34}(t)-F_{35}(t)-F_{36}(t) \\
& 0=F_{36}(t)+F_{39}(t)-F_{47}(t) \\
& 0=F_{67}(t)-F_{68}(t)-F_{70}(t) \\
& 0=F_{69}(t)+F_{70}(t)-F_{71} \\
& 0=F_{26}-F_{41}(t)-F_{45}(t) \\
& 0=F_{44}(t)+F_{45}(t)-F_{46}(t) \\
& 0=\dot{Q}_{1}(t)-\dot{Q}_{2}(t)-\dot{Q}_{3}(t) \\
& 0=\dot{Q}_{2}(t)+\dot{Q}_{4}(t)-\dot{Q}_{5}(t)
\end{aligned}
$$

where Eqs. 42-44 are for $\mathrm{H}_{2}$ storage, Eqs. 45 and 46 are for raw methanol storage, Eqs. 47 and 48 are for $\mathrm{CO}_{2}$ storage, Eqs. 49 and 50 are for heat storage, and $F_{26}$ and $F_{71}$ denote the constant flowrate of the generated $\mathrm{CO}_{2}$ from the carbon capture subsystem and the feed of raw methanol to the 
distillation subsystem, respectively.

The production is also subject to additional operational constraints. The year-round material and energy balances are bound to ensure a sustainable production, as shown in Eqs. 51-54 for $\mathrm{H}_{2}, \mathrm{CO}_{2}$, raw methanol and process heat, respectively:

$$
\begin{aligned}
& \sum_{t=1}^{N} F_{32}(t)=\sum_{t=1}^{N} F_{34}(t) \\
& \sum_{t=1}^{N} F_{41}(t)=\sum_{t=1}^{N} F_{44}(t) \\
& \sum_{t=1}^{N} F_{68}(t)=\sum_{t=1}^{N} F_{69}(t) \\
& \sum_{t=1}^{N} \dot{Q}_{3}(t)=\sum_{t=1}^{N} \dot{Q}_{4}(t)
\end{aligned}
$$

$$
0 \leqslant L^{k}(t) \leqslant L_{\max }^{k}
$$

347 Due to the flexible operation, the synthesis process is designed with a larger capacity than that for the baseline operation (i.e., without process flexibility). This constraint is modelled with Eq. 56:

$$
\dot{\xi}_{0} \leqslant \dot{\xi}_{\max }
$$

350 where $\dot{\xi}_{0}$ and $\dot{\xi}_{\max }$ denote the hourly extent of reaction at the baseline operation 
and the maximum extent of reaction designed for the flexible operation, respectively. The load fraction of a subsystem is constrained by its operability, which is modelled with Eq. 57:

$$
\phi(t) \geqslant \phi_{\min }
$$

where $\phi_{\min }$ denotes the minimum load fraction, which governs the flexibility of a subsystem.

Some of the physical bounds are redundant because the material or energy balance has implicitly imposed the constraint. For example, Eq. 53 has already been bounded due to the constant flowrate of raw methanol to the downstream DT subsystem. All redundancy has been removed prior to the solution of the optimisation model.

\subsection{Renewable energy model}

The renewable power profiles are obtained based on the meteorological data in Norderney, Germany and Kramer Junction, USA, which are locations with world class wind and solar power, respectively. Although the other renewable source in the two locations (i.e., solar power in Norderney and wind power in Kramer Junction) is unfavourable, it is considered as a complementary renewable source in modelling because diversifying the sources may help to level renewable power output [28]. The normalised meteorological data is shown in Supplementary Figure 9.

The capacity factor $(\mathrm{CF})$ of wind source is calculated based on the wind strength and the selected turbine mode, giving 29.4 and $4.3 \%$ for Norderney and Kramer Junction, respectively. The CF of solar photovoltaics (PV) for Kramer Junction is adopted from the work of Matzen et al. [29], in which they 
assumed a value of $25.0 \%$ for solar PV based on the estimated US average levelised energy cost (LEC) for renewable generation resources entering service in 2019. The CF of solar source in Norderney is calculated by comparing the solar profiles of the two locations, which gives a value of $12.1 \%$.

While the global horizontal radiation is used as available solar power, the wind power is calculated from the wind velocity. The measured wind velocity from meteorological data is first converted to the hub height using Eq. 58:

$$
U_{1}=U_{2}\left(\frac{\ln \frac{H_{1}}{z}}{\ln \frac{H_{2}}{z}}\right)
$$

where $U_{1}$ and $U_{2}$ represent the velocity at a height of $H_{1}=80$ and $H_{2}=10 \mathrm{~m}$, respectively, and $z$ represents the open ground roughness level, taken as $0.03 \mathrm{~m}$. The hub height velocity is then input to the power profile of a selected turbine (see Supplementary Figure 10) to obtain the wind power. The cut-in and cut-out speeds are set as 4 and $25 \mathrm{~m} / \mathrm{s}$, respectively [30].

Since the total power supply $\left(P_{\text {in }}\right)$, introduced earlier in Eq. 21, consists of both generated renewable power and dispatchable power, its value can be calculated by

$$
P_{\text {in }}(t)=P_{\mathrm{W}}(t)+P_{\mathrm{S}}(t)+P_{\mathrm{D}}(t)
$$

where $P_{\mathrm{W}}(t), P_{\mathrm{S}}(t)$ and $P_{\mathrm{D}}(t)$ denote the hourly wind, solar and dispatchable power at time $t$, respectively. $P_{\mathrm{D}}$ is an optional backup power, which may be a competing source to the renewable power depending on its price and policy implementation. Its impact on the overall and marginal performance of the system is of particular interest.

To quantify the renewable power generation, we introduce the provision factor, $\gamma$, to indicate the ratio of generated renewable power to production 
load requirement. Their relationship is quantified by

$$
\sum_{i} \sum_{t=1}^{N} P_{i}(t)=\gamma N \overline{P_{\mathrm{L}}}
$$

where $\overline{P_{\mathrm{L}}}$ denotes the average hourly load of the production; the subscript $i$ denotes the type of renewable source (i.e., either wind or solar). The renewable mix is indicated by the fraction of one source in the renewable power generation $\left(f_{i}\right)$, as calculated by

$$
f_{i}=\frac{\sum_{t=1}^{N} P_{i}(t)}{\gamma N \overline{P_{\mathrm{L}}}}
$$

The total dispatchable energy is essentially the summation of the hourly dispatchable energy use over the period of analysis, which is calculated by

$$
E_{\mathrm{D}}=\sum_{t=1}^{N} P_{\mathrm{D}}(t)
$$

where $E_{\mathrm{D}}$ denotes the total dispatchable energy requirement. The energy from the $\mathrm{H}_{2}$ storage subsystem ( $\mathrm{STh}$ ), termed as $E_{\mathrm{ST}}$, is always part of renewable energy since the optimiser would not schedule the dispatchable power to the storage unit. Due to the operational restrictions, all $E_{\mathrm{ST}}$ is fed to the production load, contrasting to the energy from renewable generation which may be curtailed. Thus, the portion of load met by the energy from the STh subsystem is calculated by

$$
E_{\mathrm{ST}}=\sum_{t=1}^{N}\left[a_{3}^{\mathrm{STh}} F_{35}(t)+a_{4}^{\mathrm{STh}} F_{36}(t)\right]
$$

${ }_{410}$ where $a_{3}^{\mathrm{STh}}$ and $a_{4}^{\mathrm{STh}}$ denote the specific power output per unit mass of $\mathrm{H}_{2}$ 


$$
\sum_{i} C_{i}^{\mathrm{GEN}}=\sum_{i}\left(\gamma f_{i} \overline{P_{\mathrm{L}}} \frac{1}{\mathrm{CF}_{i}} f^{\mathrm{CR}} \mathrm{CapEx}_{i}^{\mathrm{GEN}}\right)
$$

${ }_{421}$ where CapEx stands for capital expenditure. The capital recovery factor, ${ }_{422} f^{\mathrm{CR}}$, is defined by

$$
f^{\mathrm{CR}}=\frac{r(1+r)^{n}}{(1+r)^{n}-1}
$$

${ }_{423}$ where $n$ denotes the life of a unit and $r$ denotes the discount rate, taken as ${ }_{424} 8 \%$ in this work.

425 The utility consists of dispatchable energy, cooling duty and process water. ${ }_{426}$ The annual utility cost is calculated by

$$
\sum_{j} C_{j}=c_{\mathrm{D}} E_{\mathrm{D}}+c_{\mathrm{cw}} E_{\mathrm{cw}}+c_{\mathrm{pw}}\left[\sum_{t=1}^{N} F_{30}(t)-0.98 N F_{92}\right]
$$


436

where the subscript $j$ denotes the type of utilities, $c_{\mathrm{D}}, c_{\mathrm{cw}}$ and $c_{\mathrm{pw}}$ denotes the unit price of dispatchable energy, cooling duty and process water, respectively. It is assumed that the waste water stream (with a purity of $98 \mathrm{wt} \%$ ) is recycled and fed to the electrolysers. Note that Streams 1 and 11 in Figure 1 respectively represent the makeup for MEA and water losses during the operation. Their costs are neglected since the flowrate is negligible. The subsystems of the production require different cost functions due to their specific technical feature. The annualised cost of ELY and STh subsystem is determined from their maximum size, as shown in Eqs. 68 and 69:

$$
C^{\mathrm{ELY}}=x_{\mathrm{el}, \max }^{\mathrm{ELY}} f^{\mathrm{CR}} \mathrm{CapEx}^{\mathrm{ELY}}
$$

$$
\begin{aligned}
C^{\mathrm{STh}}= & L_{\max }^{\mathrm{STh}} f^{\mathrm{CR}} \mathrm{CapEx}^{\mathrm{STh}}+a_{3}^{\mathrm{STh}} F_{35, \text { max }} f^{\mathrm{CR}} \mathrm{CapEx}^{\mathrm{FC}} \\
& +a_{4}^{\mathrm{STh}} F_{36, \text { max }} f^{\mathrm{CR}} \mathrm{CapEx}^{\mathrm{TUB}}
\end{aligned}
$$

where $F_{35 \text {,max }}$ and $F_{36 \text {,max }}$ denote the maximum flowrate of $\mathrm{H}_{2}$ charged to the fuel cells and the turbine, respectively. The cost data for solid oxide fuel cells (SOFC) are used due to the maturity of this technology. The CapEx of STh subsystem includes steel tanks and compressors (as the reference provides an integrated cost [31]). The heater cost is neglected since it is negligible. Nevertheless, the electricity consumed from the heater is considered in the energy balance. The costs of subsystems of CC, SYN and DT are estimated by ratio factors based on the main equipment cost as per the work of Zhang et al. [32]. Since the subsystems of CC and DT are non-flexible, their annualised cost is independent of the size, as shown respectively in Eqs. 70 and 71:

$$
\begin{aligned}
& C^{\mathrm{CC}}=f^{\mathrm{CR}} \mathrm{TFCC}^{\mathrm{CC}} \\
& C^{\mathrm{DT}}=f^{\mathrm{CR}} \mathrm{TFCC}^{\mathrm{DT}}
\end{aligned}
$$


where $\mathrm{TFCC}^{k}$ stands for the total fixed capital cost of $k$ subsystem. Due to the flexible feature of SYN subsystem, its annualised cost is estimated via the six-tenths factor rule based on the size. Therefore, the annualised cost of SYN is calculated by

$$
C^{\mathrm{SYN}}=\left[26.76 \times 10^{6}+\mathrm{TFCC}^{\mathrm{SYN}}\left(\frac{\dot{\xi}_{\mathrm{max}}}{\dot{\xi}_{0}}\right)^{0.6}\right] f^{\mathrm{CR}}
$$

where TFCC ${ }^{\text {SYN }}$ denotes the total fixed capital cost of SYN (barring MCP1 unit) at the baseline operation (its size is measured in terms of extent of reaction, i.e., $\left.\dot{\xi}_{0}\right)$. The constant coefficient in Eq. 72 represents the TFCC of MCP1 unit. The actual size of SYN taking flexibility into account is denoted by $\dot{\xi}_{\max }$, which is obtained from the optimiser. Note that TFCC ${ }^{\text {SYN }}$ excludes the MCP1 unit because the latter is independent of the SYN size (due to constant flowrate $F_{26}$ ). The main equipment costs for the production subsystems are given in Supplementary Table 13. The breakdown of all subsystems TFCC at the baseline operation is given in Supplementary Table 17.

The storage unit for liquefied $\mathrm{CO}_{2}$ and raw $\mathrm{MeOH}$ is essentially a pressure vessel, of which the cost can be estimated from empirical correlations using the Douglas's method [33]. While the cost function of a pressure vessel can benefit from the economies of scale, the capacity of a single vessel has to be constrained. From an initial estimate, it is found that the required storage size is in the range of thousands tonnes, which is way above a single vessel capacity. Therefore, the cost functions for STm and STc are modified to

$$
\begin{aligned}
C^{\mathrm{STc}} & =107.3 L_{\max }^{\mathrm{STc}} \\
C^{\mathrm{STm}} & =53.1 L_{\max }^{\mathrm{STm}}
\end{aligned}
$$


where the pre-variable constants represent the cost per unit mass based on a single vessel capacity of 200 tonnes. The capital costs of the cooler and the heater in STc are ignored due to their insignificant magnitudes. Full derivation from the empirical correlations to the linearised approximation is elaborated in Supplementary Note 1. Regarding the heat storage, a thermo-chemical ESS is used in this work due to its maturity in large-scale applications [34]. The annualised cost for STq is calculated by

$$
C^{\mathrm{STq}}=L_{\max }^{\mathrm{STq}} f^{\mathrm{CR}} \mathrm{CapEx} \mathrm{x}^{\mathrm{STq}}+\dot{Q}_{4, \max } \mathrm{OpEx} \mathrm{x}^{\mathrm{STq}}
$$

where OpEx stands for operational expenditure and $\dot{Q}_{4, \max }$ denotes the maximum discharging rate of the STq subsystem.

The raw materials and utility costs are summarised in Supplementary Table 18, while the cost parameters for renewable generation, electrolysers and storage technologies are tabulated in Supplementary Table 19.

\subsection{Optimisation strategy}

The aim of the modelling is to minimise the levelised cost of methanol (LCOMeOH, measured in $\$ /$ tonne) by optimising the energy and material dispatch supported by the suitable sizing of all units operating flexibly. This leads to an objective function defined by

$$
\mathrm{LCOMeOH}=\frac{1}{0.001 N F_{88}}\left(\sum_{i} C_{i}^{\mathrm{GEN}}+\sum_{j} C_{j}+\sum_{k} C^{k}\right)
$$

where the notation $i$ denotes the source of renewable energy, $j$ denotes the type of utility and $k$ denotes the subsystem. The annualised cost terms are introduced in Eqs. 65-75, respectively. The denominator, $0.001 N F_{88}$, 
denotes the annual production of $\mathrm{MeOH}$ measured in tonne. The optimisation problem is summarised as follows:

$\begin{array}{lll}\text { min. } & \text { Objective function } & \text { Eq. } 76 \\ \text { s.t. } & \text { System models } & \text { Eqs. } 21-50 \\ & \text { Operational constraints } & \text { Eqs. } 51-57 \\ & \text { Specifications } & \text { Supplementary Table } 15\end{array}$

The key decision variables to be determined by the optimisation are listed in Supplementary Table 14. All constant parameters in the physical and renewable energy model are summarised in Supplementary Table 15. For a given set of parameters, the solution of the optimisation problem will indicate the corresponding optimal dispatch of the material and energy flows. A qualitative illustrative example is given by Supplementary Figure 11.

To reduce the computational complexity, we have applied linearisation techniques including cost functions linear approximation (see Eqs. 73 and 74), bilinear variables replacement (for Eq. 34) and storage level reformulation to avoid discontinuities (for Eqs. 38-41). The modification results in a linear programming model, which is implemented in GAMS (General Algebraic Modelling System) and solved using the CPLEX solver.

\subsection{Summary of assumptions}

The following assumptions have been used in this work: (1) the analysis focuses on one year operation with no downtime of methanol production. (2) All process units are assumed to have a life of 30 years. (3) Makeup streams in carbon capture process are excluded in costing because the materials loss 
is negligible. (4) The energy from the purge stream is ignored since it is difficult to recover the heat from process flare. (5) The compressors modelled in this work are assumed to be isentropic with an efficiency of $75 \%$. (6) All mechanical work and process heating (except the integrated heating) are powered by electricity only. (7) The electrolysers can ramp instantaneously from $0-100 \%$. (8) The storage units are not limited by charging or discharging rate. (9) The standby losses of energy and material in the storage units are neglected.

\section{Results}

The optimisation results are shown to be strongly affected by two factors, i.e., the dispatchable energy price and the degree of process flexibility, which are of special interest from both policy making and engineering perspectives. We first evaluate a base case scenario with fixed values for these two parameters, which renders a detailed cost breakdown and yields insight into the impact of process flexibility on key design choices. Subsequently, the analysis scope extends to explore the impact of dispatchable energy price and process flexibility on the (minimised) methanol production cost and the corresponding penetration level of renewables. A separate analysis focuses further on the environmental perspective, exploring how the intended penetration level of renewables would alter the economics with or without process flexibility. Recognising the uncertainties in the technology costs, we finally offer economic assessments of a conservative and a progressive scenario for costing, to test the robustness of the observations made from the base case scenario. 


\subsection{Base case scenario}

The base case scenario is defined by using fixed dispatchable energy price $\left(c_{\mathrm{D}}\right)$ and flexibility of the methanol plant. The purchase of dispatchable electricity plays an important role in determining the overall economic performance; its price can be used as a tool to influence the renewable penetration in chemical production [35] and can be highly volatile subject to both local policies and market conditions. For Germany, an electricity price of $57 \$ / \mathrm{MWh}$ (50€/MWh) was quoted in a previous study [36], while a recent work provided more insights into electricity purchase by taking spot market price, taxation, fees, subsidies and apportionments into account, reporting a price range from 35 to $166 \$ / M W h$ [14]. Regarding the US, the average electricity price ranges from 103 to $128 \$ /$ MWh depending on end-use sectors [37]. For easy comparison, our base case scenario uses a benchmark price of $100 \$ / \mathrm{MWh}$ for the dispatchable energy in both locations.

On process flexibility, the base case scenario considers no lower limit on the load fraction of electrolysers [27], but applies a minimum load $\left(\phi_{\min }\right)$ for the synthesis reactor. In principle, the load range of a catalytic reactor depends on the nature of the chemical reactions, catalysts and the reactor design, and is limited by key operational issues such as temperature management [11]. Currently, there is no experimental or theoretical data available regarding the load range of a methanol synthesis reactor. Matthischke et al. has investigated the load range of an adiabatic reactor for $\mathrm{CO}_{2}$ methanation using superficial velocity as a basis, which translates to a minimum load fraction of $9.8 \%$ [12]. Nayak-Luke et al. has used a minimum load fraction of $20 \%$ for ammonia synthesis [7]. In our current study, the value of $\phi_{\min }$ is assumed to be $10 \%$ for the base case scenario, further with a range of $\phi_{\min }$ investigated to elaborate 
the impact of flexibility on the overall performance of the system.

Table 1 summarises the key indicators for the most economical performance of the base case scenario in both locations. These operation indicators include the renewable energy provision $(\gamma)$, renewable penetration $\left(f_{\mathrm{L}}^{\mathrm{RE}}\right)$ and renewable mix measured in terms of wind fraction in power generation $\left(f_{\mathrm{W}}\right)$. Regarding Norderney, the flexible process offers a moderate reduction to the $\mathrm{LCOMeOH}$ compared with the non-flexible process, but it achieves a significantly greater level of renewable penetration (90 vs. $48 \%$ ). This implies a significantly improved environmental performance at a (albeit slightly) lower cost when flexible production is implemented. The renewable mix indicates that only wind power is generated for the case of Norderney. As for Kramer Junction, the improvement caused by the flexible production is insignificant for both the production cost (933 vs. $946 \$ /$ tonne) and the level of renewable penetration (81 vs. $73 \%$ ). This is because the mitigation of the variable input power, which is where the benefits of a flexible process would be derived, is in this case already tackled economically by the excess provision of renewable (solar) power. That is, with relatively cheap renewable power, the benefits from a flexible process would be limited.

Table 1. Optimal performance of the base case scenario, where $c_{\mathrm{D}}$ is fixed at $100 \$ / \mathrm{MWh}$ and $\phi_{\min }$ at $10 \%$ for the flexible production.

\begin{tabular}{lllllll}
\hline \hline \multirow{2}{*}{ Location } & \multirow{2}{*}{ Flexibility } & LCOMeOH & LEC & $\gamma$ & $f_{\mathrm{L}}^{\mathrm{RE}}$ & $f_{\mathrm{W}}$ \\
& & $\$ /$ tonne & $\$ / \mathrm{MWh}$ & - & $\%$ & $\%$ \\
\hline \multirow{2}{*}{ Norderney } & Flexible & 960.8 & 64.9 & 0.70 & 90.1 & 100 \\
& Non-flexible & $1,046.7$ & 78.9 & 0.39 & 48.3 & 100 \\
\multirow{2}{*}{ Kramer Junction } & Flexible & 932.6 & 62.7 & 0.66 & 81.3 & 0 \\
& Non-flexible & 946.0 & 66.1 & 0.61 & 73.0 & 0 \\
\hline \hline
\end{tabular}

Further inspection of the limited economic improvement by process flexibility shows that the benefit is restricted by the level of renewable penetration in the design that minimises the production cost. Figure $2 \mathrm{~A}$ and $\mathrm{B}$ compare the 
current most economical case with an enforced fully renewable operation (i.e., $f_{\mathrm{L}}^{\mathrm{RE}}=100 \%$ ) for both locations, with a detailed display of the cost elements contributing to $\mathrm{LCOMeOH}$. The potential benefits of a flexible production are fully demonstrated when a $100 \%$ renewable operation is imposed, wherein the cost saving is mainly attributed to the cost reduction in the $\mathrm{H}_{2}$ storage (Norderney) and renewable power generation (Kramer Junction). The reliance of $\mathrm{H}_{2}$ storage is reduced because the variability of renewable sources is tackled by the alternative subsystems, i.e., $\mathrm{CO}_{2}$ and raw methanol storage, which are much cheaper than $\mathrm{H}_{2}$ storage. The substitution of energy storage using material buffer is achieved by the flexible production at an additional cost of the (over-sized) synthesis units. Clearly, the overall saving from a flexible operation significantly outweighs the additional costs.

In addition to the saving from the $\mathrm{H}_{2}$ storage subsystem, a flexible operation also reduces the renewable generation cost in the fully renewable case (Figure $2 \mathrm{~B}$, upper). If the renewable generation is relatively cheap, which is the case for Kramer Junction, the excess provision of renewable power may occur in lieu with renewable energy storage (i.e., the $\mathrm{H}_{2}$-based ESS). The benefits of process flexibility in such a case would be mainly from the reduction of the renewable over-provision. The optimisation result confirms that the process flexibility would lead to reduced curtailment, which represents improved utilisation of renewable energy (see Supplementary Figure 13). Note however that the flexible operation for the most economical scenario in both locations (Figure 2A and $\mathrm{B}$, lower) incurs a higher renewable generation cost despite the reduction of the overall cost. This corresponds to an increase in renewable energy intake, which is made more affordable (compared with the use of dispatchable energy) thanks to the process flexibility.

To further elucidate the impact of the variability of renewable energy on 

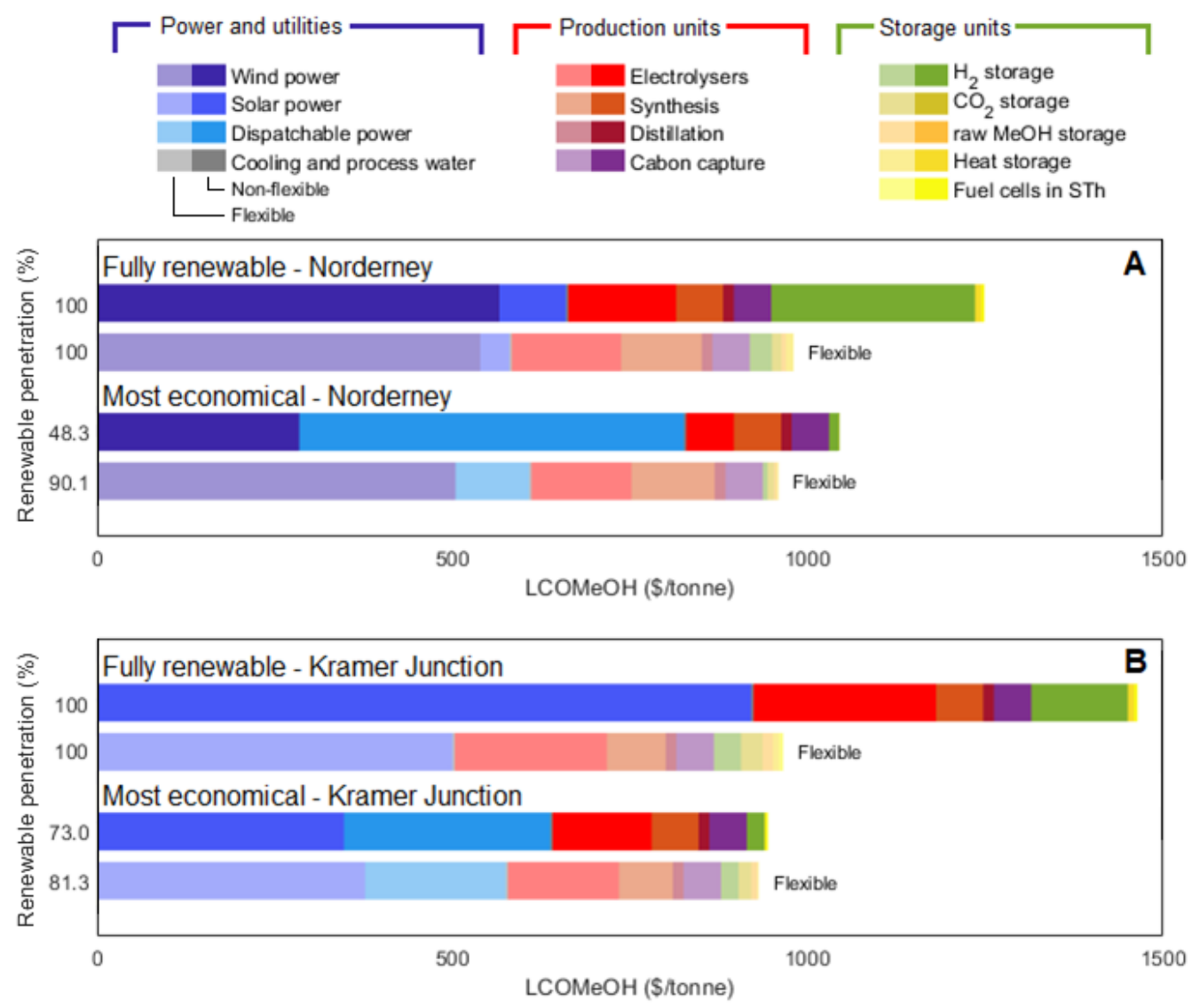

Figure 2. Contribution of the cost elements to $\mathrm{LCOMeOH}$ in the most economical case and the $100 \%$ renewable operation case for (A) Norderney and (B) Kramer Junction. Note that the costs of $\mathrm{H}_{2}$ storage includes tanks and compressors. Shaded areas indicate the flexible processes.

the potential benefits of process flexibility, the upper panels of Figure 2A and B compare the fully renewable operation scenarios for the two locations (see Supplementary Table 22 for the detailed cost elements and the associated sizes of individual units). The fully renewable operation (without flexibility) in Kramer Junction is much more expensive than that in Norderney $(1,466$ vs. $1,251 \$$ /tonne), even though the solar (the major renewable source in Kramer Junction) technology is cheaper than wind (the major renewable source in Norderney). The $\mathrm{LCOMeOH}$ difference can be attributed to the characteristics of the renewable sources. Between the two locations, the variability of the 
solar power source in Kramer Junction is significantly greater than that of the wind power source in Norderney (see Supplementary Figure 9). One can see from the upper panels of Figure 2A and B that, without process flexibility, the $\mathrm{LCOMeOH}$ for Kramer Junction is approximately $17 \%$ higher than its counterpart of Norderney, which is largely due to the excess solar energy generation needed to handle its high variability. By introducing process flexibility, the excess generation is greatly circumvented. Consequently, the $\mathrm{LCOMeOH}$ for Kramer Junction is significantly reduced, which becomes even cheaper than its counterpart of Norderney (967 vs. $982 \$ /$ tonne). In the case of Kramer Junction, process flexibility reduces its LCOMeOH by approximately $34 \%$; in comparison, the reduction is $22 \%$ for Norderney. This indicates that the potential benefits of a flexible production would be more significant if the renewable energy source is more variable.

Although the ramping of the synthetic reactor is not constrained in the base case scenario, analyses have been performed to verify the impact of ramping on system performance. Currently, there is no literature reporting the ramp limit of a methanol reactor. However, Armijo and Philibert reported an hourly ramp limit of $20 \%$ (based on the rated capacity) for ammonia reactors [38]. In light of this, key variables are reported at selected ramp limits up to $20 \%$ (for both ramp-up and -down) for operations in Norderney as an example, which are tabulated in Supplementary Table 23. Significantly, at $20 \%$ ramp limit the $\mathrm{LCOMeOH}$ is almost same as the unlimited case (982.4 vs. $982.2 \$ /$ tonne for Norderney). Further inspection on ramp limit shows that the reduction of $\mathrm{LCOMeOH}$ due to the relaxing of ramp limit results from the saving of $\mathrm{H}_{2}$ storage, which is in accordance with the benefits of flexibility. In fact, ramp constraint is an alternative measure of the process flexibility. Examples of the methanol reactor load at selected ramp limits are 
plotted in Supplementary Figure 14.

\subsection{Impact of dispatchable energy price and process flexibility}

The above analysis focuses on the base case scenario, wherein a constant dispatchable energy price (reflects the current market) and a fixed flexibility (reflects the technology limits) have been chosen. Given that the market and technology may change, it is of special interest to know how the dispatchable energy price and flexibility limits impact on the overall economical potential. Thus, the trend of $\mathrm{LCOMeOH}$ and its corresponding renewable penetration $\left(f_{\mathrm{L}}^{\mathrm{RE}}\right)$ are plotted in Figure 3 for a range of dispatchable energy price $\left(c_{\mathrm{D}}\right)$ at selected levels of process flexibility indicated by the minimum load of the methanol reactor $\left(\phi_{\min }\right)$. Regardless of the location, $\mathrm{LCOMeOH}$ and $f_{\mathrm{L}}^{\mathrm{RE}}$ share the same trend: both significantly increase with $c_{\mathrm{D}}$ initially, followed by a much reduced increase rate subsequently. The critical point that divides the two-regime behaviour is at a dispatchable energy price around $120 \$ / \mathrm{MWh}$ for both locations. Note that the non-flexible production means $\phi_{\min }=1$, i.e., the methanol synthesis subsystem is always at its full load.

From Figure 3A and $\mathrm{C}$, it can be seen that the degree of reduction in $\mathrm{LCOMeOH}$ due to process flexibility is directly affected by the price of dispatchable energy; the economic benefit becomes more noticeable only after $c_{\mathrm{D}}$ is higher than a certain level, as it drives the increase in renewable penetration and hence the importance of process flexibility to handle the increased variable energy supply. Ultimately, the saving from introducing flexibility is capped by the $\mathrm{LCOMeOH}$ difference at a fully renewable operation (see Figure 2). In Figure 3C, the $\mathrm{LCOMeOH}$ reduction between $\phi_{\min }=0.1$ 

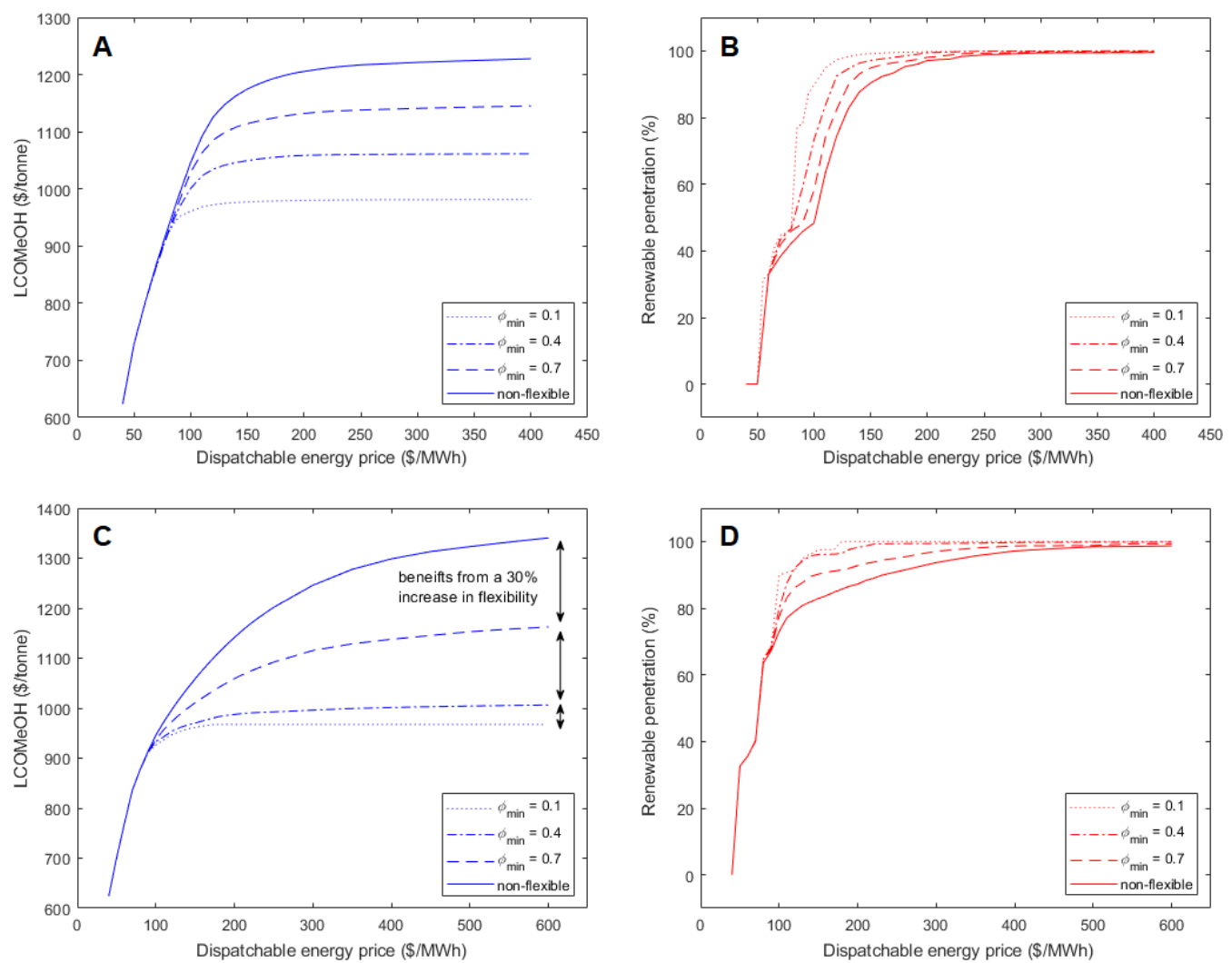

Figure 3. Optimal LCOMeOH and its corresponding renewable penetration at different process flexibility over a range of dispatchable energy price. (A) and (B) are plotted for Norderney; (C) and (D) for Kramer Junction.

and 0.4 is much smaller than the reduction between $\phi_{\min }=0.4$ and 0.7 or that between 0.7 and 1 (i.e., the non-flexible case). This indicates that the benefits of a flexible process may exist only within a limited range of flexibility, beyond which further gains could vanish.

The corresponding trends of $f_{\mathrm{L}}^{\mathrm{RE}}$ are shown in Figure 3B and D. In general, the flexible processes tend to facilitate the use of renewable power, hence the increase in renewable penetration at a given $c_{\mathrm{D}}$. However, this environmental benefit gradually vanishes when the dispatchable energy price increases, as the renewable penetration at all levels of flexibility approaches $100 \%$. The exact shape of a $f_{\mathrm{L}}^{\mathrm{RE}}$ curve, on the other hand, is the result of the (economically) 
optimal selection and the combination of measures that can contribute to the handling of variable energy supply. These measures include the sizing of electrolysers and the synthesis reactor as well as the adoption and sizing of $\mathrm{H}_{2}$ and other in-process storage subsystems. A detailed analysis on the introduction of these measures along with the increase of $c_{\mathrm{D}}$ is provided in Supplementary Figure 12.

\subsection{Costs of enforced renewable penetration targets}

Although the dispatchable energy price may be used as an economic tool to steer renewable penetration, its influence on achieving the desirable targets is limited by the two-regime behaviour of $f_{\mathrm{L}}^{\mathrm{RE}}$ profiles (see Figure $3 \mathrm{~B}$ and D), which makes it less effective after the critical point as $f_{\mathrm{L}}^{\mathrm{RE}}$ becomes insensitive to $c_{\mathrm{D}}$. Even with dispatchable energy prices below the critical point, its increase would result in a dramatic rise in $\mathrm{LCOMeOH}$ accompanying the increase of $f_{\mathrm{L}}^{\mathrm{RE}}$. Here, we explore the economic implication of directly enforcing the environmental targets, i.e., the levels of renewable penetration, based on the $\mathrm{LCOMeOH}$ and the breakdown of the cost elements obtained from the optimisation model with an added equality constraint on $f_{\mathrm{L}}^{\mathrm{RE}}$.

Figure 4 shows the $\mathrm{LCOMeOH}$ at targeted $f_{\mathrm{L}}^{\mathrm{RE}}$ ranging from 90 to $100 \%$, a region with high renewable penetration where a flexible process is expected to be important (low renewable penetration reduces the impact of flexibility, as illustrated earlier in Figure 3). The two locations feature similar trends in the total cost variation but show different weights of individual cost elements, which is attributed to the difference in both renewable source characteristics and technology prices. The costs of renewable power generation account for more than half of the total $\mathrm{LCOMeOH}$ for both locations. Barring the renewable power costs, the cost elements for all cases are plotted in Figure 
$4 a-d$ on the same scale. Clearly, the benefits of flexible production, which is achieved by producing excess raw methanol using the surplus renewable power, are shown to arise primarily from the reduction in $\mathrm{H}_{2}$ storage cost (more significant for Norderney) and renewable generation cost (more significant for Kramer Junction) throughout the range of renewable penetration. The three completing factors - flexibility, $\mathrm{H}_{2}$-based ESS and renewable power overprovision-form an interplay triangle (see the scheme in Figure 4, upper-left). Thus, the cost reduction of a particular element from introducing flexibility greatly depends on the existing trade-off between the other two "competing" factors. Note that the cost of $\mathrm{CO}_{2}$ storage is conjugated with raw methanol in accordance with material balance and the reaction stoichiometry.

In Kramer Junction, the costs of $\mathrm{H}_{2}$ storage and fuel cells are insignificant (compared to Norderney), yet they play a more important role for this site. This is because more $\mathrm{H}_{2}$ is used as a fuel (as opposed to feedstock for methanol synthesis) in this case, which is indicated by the fraction of load met by the energy from the $\mathrm{H}_{2}$ storage unit (see Supplementary Figure 15). This is also attributed to the characteristics of the solar power in Kramer Junction, i.e., its diurnal variation leads to complete (renewable) power outage during the nights, thus requiring larger fuel cells to sustain a minimum production rate.

Another noteworthy feature in Figure 4 is the significant increase in the overall cost from $f_{\mathrm{L}}^{\mathrm{RE}}=99$ to $100 \%$ in the non-flexible processes, which is largely mitigated in the flexible processes. This cost increase originates from two different sources for the two locations. In the case of Norderney, a significant increase in the cost originates from the $\mathrm{H}_{2}$ storage unit. Interestingly, the increase in $\mathrm{H}_{2}$ storage unit does not lead to an increased energy use from the fuel cells (see Supplementary Figure 15). To further probe the mechanism of the cost increase, profiles of energy and materials dispatch are 

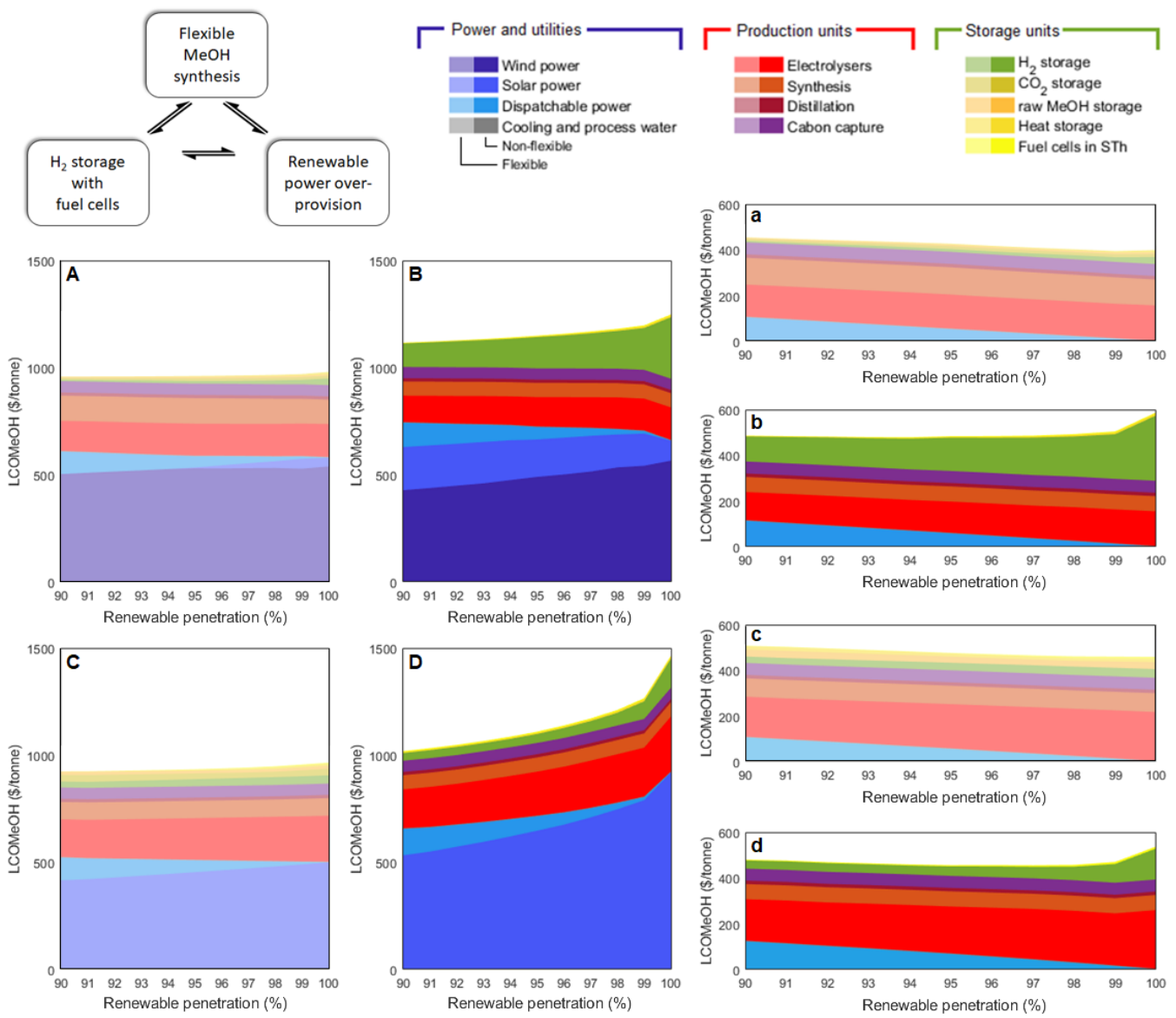

Figure 4. Cost of production at targeted renewable penetration. (A) Flexible process for Norderney; (B) non-flexible process for Norderney; (C) flexible process for Kramer Junction; (D) non-flexible process for Kramer Junction. Subsets (a)-(d) illustrate the enlarged cost elements by excluding renewable power costs, which respectively correspond to (A)-(D). The upper-left triangle schematic illustrates the interplay between three measures for mitigating the variable renewable power.

investigated. It can be seen that the average load of the whole production significantly reduces from $584 \mathrm{MW}$ at $f_{\mathrm{L}}^{\mathrm{RE}}=99 \%$ to $536 \mathrm{MW}$ at $f_{\mathrm{L}}^{\mathrm{RE}}=100 \%$ (see Supplementary Figure 16), which is attributed to the increase of electrolyser efficiency. Due to the inverse correlation between electrolysers load and energy efficiency (see Eq. 20), a higher overall energy efficiency means a lower capacity factor. Significantly, the operation profiles of electrolysers show a full load hour equivalent of 3,283 at $f_{\mathrm{L}}^{\mathrm{RE}}=99 \%$ and 2,868 at $f_{\mathrm{L}}^{\mathrm{RE}}=100 \%$. 
Thus, the increase in $\mathrm{H}_{2}$ storage results from the change of the optimal power dispatch to electrolysers. Regarding Kramer Junction, the significant increase in overall cost from 99 to $100 \%$ renewable operation is mainly attributed to the excess solar power generation, which is preferred due to the cheaper solar PV costs (thus facilitating the over-provision of solar power). As a result, the renewable power curtailment becomes significantly higher at $f_{\mathrm{L}}^{\mathrm{RE}}=100 \%$ (see Supplementary Figure 13).

The above observation is consistent with the work of Budischak et al., in which they reported a significant increase in the storage units capacity when the load met by renewable energy was increased from 90 to $99.9 \%$ [39]. This result may question the policymakers on the necessity of achieving fully renewable energy supply as a small fraction of dispatchable power would significantly reduce the overall cost. On the other hand, the results shown here suggest that introducing process flexibility can help easing the tension between economics and environmental targets.

It is worth noting that for a non-flexible electrified chemical process, its optimised production cost is dictated by the optimised cost of energy, as the chemical process in such a case merely plays a role of a fixed demand and offers no room for optimisation. In power-to-methanol, the design that leads to a minimum LEC would also lead to a minimum LCOMeOH. In a system with process flexibility, however, the interplay between subsystems means that the value of LEC is unable to indicate the optimality of the whole system. Concretely, the functionality of the units overlaps as the over-sized synthetic reactor improves the economics of energy utilisation, of which the additional cost is however outside the boundary of power generation (thus not reflected in LEC). The flexible production also entails a variable load, contrasting to the constant load for a non-flexible production. The variable load and energy 
costs at are plotted in Supplementary Figures 16 and 17, respectively.

Although previous reports have stressed the importance of complementary renewable mix in balancing demand and supply (e.g., Ref. [40]), only Norderney has shown to have a fraction of the complementary source (i.e., solar source) in the optimal renewable power generation. Kramer Junction has shown no incorporation of the complementary source (i.e., wind source) in all operation scenarios. The sole renewable source in power generation for Kramer Junction can be ascribed to the low capacity factor (CF) of the other source: the CF is $25.0 \%$ for solar and $4.3 \%$ for wind power in Kramer Junction (the value of CF is calculated based on the meteorological data and selected renewable technology, see Methods). In contrast, the CF is $29.4 \%$ for wind and $12.1 \%$ for solar power in Norderney. It is believed that if a location has multiple renewable sources of similar availability or variability (which results in a similar $\mathrm{CF}$ ), a sophisticated renewable mix would be expected in its power generation.

\subsection{Cost comparison and impact of technology prices}

The range of the production cost is compared with previous studies. For example, Bos et al. reported a cost range of 750-800 €/tonne (or 887-946 $\$$ /tonne) for renewable methanol produced from air captured $\mathrm{CO}_{2}$, water and renewable electricity [8], which is comparable to our results. Gonzalez-Garay et al. reported the production cost of renewable methanol produced from a wide range of routes, including $\mathrm{H}_{2}$ from solar, wind, nuclear and biomass and $\mathrm{CO}_{2}$ from coal, natural gas and air [17]. Thus, a wide range of methanol cost can be seen from their work, which is from 1,200 to $2,500 \$$ /tonne.

Apart from the production routes, another issue commonly facing techno- 
Table 2. Optimal LCOMeOH for $100 \%$ renewable operations based on conservative and progressive technology costs.

\begin{tabular}{llll}
\hline \hline \multirow{2}{*}{ Location } & \multirow{2}{*}{ Flexibility } & \multicolumn{2}{c}{ LCOMeOH ( \$/tonne) } \\
\cline { 3 - 4 } Norderney & Flexible & $1,496.1$ & 787.0 \\
& Non-flexible & $1,885.3$ & $1,036.2$ \\
& Reduction due to flexibility (\%) & 20.6 & 24.0 \\
& & & \\
\multirow{2}{*}{ Kramer Junction } & Flexible & $1,851.8$ & 776.8 \\
& Non-flexible & $2,840.7$ & $1,159.1$ \\
& Reduction due to flexibility (\%) & 34.8 & 32.8 \\
\hline \hline
\end{tabular}




\section{Discussion}

The results of this study show clear potential of process flexibility in facilitating the integration of variable renewable energy (VRE) into a chemical process, by accommodating the variability of renewable sources with reduced reliance on expensive VRE over-provision and its subsequent storage. However, for a viable flexibility implementation there are two prerequisites derived from the interplay triangle shown in Figure 4: (1) the cost of the core flexible chemical process units, i.e., those that need to be over-sized to enable load adjustment, should not be a dominant element in the total production cost, and (2) the storage cost for intermediate products in the chemical process - incurred due to the need for handling flexibility disparity between process units - should be sufficiently lower than the energy storage system for VRE. Generally, the cap of the benefits from a flexible process can be calculated from the extent to which the above two prerequisites are met. In our case study, the cap is sufficiently large so that a flexible process would be economically justified for a wide range of operation scenarios. In particular, the methanol synthesis process produces raw methanol as an intermediate product, of which the storage cost is much cheaper than that of $\mathrm{H}_{2}$ for storing surplus VRE. This however may not be always true for other chemical processes and will depend on the nature of their process units and that of their intermediate products, although broadly speaking the storage costs of chemicals are likely to be lower than that of $\mathrm{H}_{2}$ given the particularly high cost of the latter with the currently available technology. Furthermore, it has been clearly shown in this work that the positive role of process flexibility becomes more significant with a large penetration of highly variable sources, which is an important factor to be considered when assessing its suitability in a particular local context. 
While a flexible process allows space for optimising the energy and material dispatch potentially leading to a reduced overall cost, its implementation brings additional complications to energy integration, an energy saving measure widely adopted in modern chemical processes. In the methanol case study, this is reflected by the need for introducing a heat storage between methanol synthesis (heat source) and carbon capture (heat sink), to coordinate the heat recovery between the two subsystems which frequently operate at different load levels. In a chemical process that requires a more sophisticated heat exchanger network, heat storage mediated integration could become economically nonviable; the introduction of process flexibility would thus entail a significant opportunity cost of energy integration. In a sense, process flexibility is a competing design to process integration; its implementation requires an analysis on a case-by-case basis. Nevertheless, if the range of cost reduction (20-35\%) brought by implementing process flexibility as demonstrated in this work can be attained, its potential gains would most likely exceed the opportunity cost of energy integration for many chemical processes. On the other hand, we envision that the smart design of energy integration dedicated to flexible production may be a focus of future research. In our case study, we have demonstrated a MVR system implemented in the distillation process as an example of energy integration strategy guided by two principles: (1) maximising the energy integration within a subsystem and (2) minimising the energy integration across different subsystems. Similar principles have previously been adopted in processes with sections subject to different production schedules (e.g., Ref. [43]), and may be further developed for flexible production to enable the integration of variable renewables.

The formulation of the optimisation simplifies the heat storage model by assuming all heat generated by the methanol reactor will be stored and 
then consumed by the reboiler in the carbon capture subsystem. Thus, it is necessary to verify the validity of this formulation by checking the levelised heating cost (via the heat storage unit), which is found to be 19.7 and 15.8 \$/MWh for Norderney and Kramer Junction, respectively. These costs are sufficiently lower than the electrical heating, and thus the simplification in formulation does not affect the economics. On the other hand, if the levelised heating cost is expensive (e.g., above $100 \$ / M W h$ ), the formulation should be revised to allow heat curtailment.

In a case where process flexibility leads to a net economic gain, this gain is not merely shaped by the flexibility available in chemical production, but rather a consequence of the holistic optimisation of the whole system that includes also electrolysis and $\mathrm{H}_{2}$-based ESS. In this work, the modelling of electrolysis considered the variation of its efficiency with load [27]. While a simple assumption of a constant electrolyser efficiency is often adopted in the present literature (e.g., Ref. [7]), the overall design of the power-to-methanol system in this work is shown to be clearly benefited from the optimal trade-off between an improved energy use efficiency (which increases at lower load fractions) and an additional capital cost of electrolysers (arising from capacity over-sizing). This points to the importance of considering a load-dependent efficiency of electrolysers in the future work on any system where electrolysis dominates the overall energy consumption. From a modelling point of view, the inclusion of a load-dependent efficiency would increase the complexity of the mathematical model. In this work, a linear efficiency-load function is adopted for electrolysis to reduce the complexity introduced (see Eq. 20). This still caused a bilinear term in one of the model equations (arising from the combination of Eqs. 29 and 34) and required a linearisation technique to retain the linearity of the optimisation model. Note that a more accurate 
efficiency-load function is more likely to be nonlinear and concave [27], which would predict a higher energy efficiency compared with that modelled by a linear function, although the use of such a function will lead to a more complex mathematical model.

The sensitivity study in this work shows that, with a certain range, the level of process flexibility significantly affects the potential economic gain, which calls for rigorous assessment of the attainable load range of any chemical processes to be integrated with renewable energy. A similar study has been performed focusing on ammonia reactors [11]; however, the operationality of methanol reactors is yet to be investigated. Such studies will not only indicate an operation envelop of the flexible processes, but also offer detailed analyses of the dynamic behaviour of the chemical production [12], which has not been considered in this work. The knowledge on the dynamic responses should be used to determine the ramping rate at which the load level of a process unit can vary, which may impose additional constraints that need to be considered in determining the optimal allocation of "duties" between VRE storage and process flexibility for handling the variability of energy supply. More importantly, the dynamic behaviours help to identify the fluctuation in product specifications at the reactor outlet. Another future direction lies in the development of optimisation techniques for renewable chemical production. In the current work, the optimisation model can only deal with one particular flowsheet. The optimisation of a superstructure composed of different process designs is challenging at the present. Such sophisticated optimisation tasks could be handled in the future by making use of novel methods developed for energy optimisation [44] and production planning [45] in complex chemical systems. 


\section{Conclusions}

Using methanol production as an example for electrification and the use of renewable energy in chemical industry, this work reveals clear potential of incorporating load flexibility in the chemical processes to improve the economics of integrating variable renewable energy. The demonstrated benefits of process flexibility arise from reduced expensive energy $\left(\mathrm{H}_{2}\right)$ storage (when the renewable generation is expensive) and, in certain cases, improved energy utilisation due to the reduction of curtailment and energy conversion losses (when the renewable generation is cheap). The process flexibility enabled design has been shown to be particularly beneficial when the renewable energy supply is highly variable and when the desirable level of renewable penetration is high. The implementation of a flexible production requires over-sizing of the flexible process units. It also requires storage units for the intermediate products and for energy to be exchanged between different process units, to allow these units to operate at different load levels. In the methanol case study, these additional "flexibility" costs are outweighed by the economic gains. This cost-benefit analysis needs to be evaluated on a case-by-case basis when applying the flexibility concept elsewhere, bearing in mind that the relatively small cost portion attributed to the flexible process unit (the synthesis reactor) and the moderate physical conditions for the additional storage units are among the key factors leading to favourable economics in the methanol example. Where these factors hold true, this work demonstrates that systematically optimised design that makes the best combination of energy storage and process flexibility may offer a viable route for future sustainable chemical production powered by renewables, which deserves attention from both industrial policy making and engineering practices. 


\section{${ }_{916}$ Acknowledgements}

917

CC thanks the China Scholarship Council and Jesus College, Oxford for funding the studentship. The authors wish to thank Dr. Guoping Hu for a critical review of the manuscript.

\section{Additional Information}

Supplementary information is available for this paper.

The GAMS code is available from the corresponding author upon request.

\section{Author information}

Corresponding Author

*E-mail: aidong.yang@eng.ox.ac.uk

ORCID

Chao Chen: 0000-0002-4924-9558

Aidong Yang: 0000-0001-5974-247X

\section{Author contributions}

Both authors contributed to the concept. CC synthesised the process flowsheets, carried out process simulations, constructed and solved the optimisation model, analysed the results and led the manuscript writing. AY supervised the project, improved the optimisation model and contributed to the manuscript writing. 


\section{Competing interests}

${ }_{936}$ The authors declare no competing financial interest.

\section{${ }_{937}$ Nomenclature}

${ }_{938}$ Abbreviations

CapEx capital expenditure

CF capacity factor

ESS energy straoge system

LCOMeOH levelised methanol cost

LEC levelised energy cost

LREC levelised renewable energy cost

MEA monoethanolamine

$\mathrm{MeOH}$ methanol

MVR mechanical vapour recompression

OpEx operational expenditure

PV photovoltaic

SOFC solid oxide fuel cell

TFCC total fixed capital cost

VRE variable renewable energy

\section{Parameters}

$a^{k} \quad$ constant utility coefficient for subsystem $k$

$b \quad$ constant material coefficient

$c_{j} \quad$ unit price of utility $j(\$ / \mathrm{kg}$ or $\$ / \mathrm{kWh})$

$C_{j} \quad$ annualised cost of utility $j$ (\$/year)

$C^{k} \quad$ annualised cost of subsystem $k$ (\$/year) 


\begin{tabular}{|c|c|}
\hline$e^{\mathrm{ELY}}$ & specific energy requirement for electrolyser $\left(\mathrm{kWh} / \mathrm{kg}_{\mathrm{H}_{2}}\right)$ \\
\hline$E_{\mathrm{a}}$ & activation energy for reactions $(\mathrm{J} / \mathrm{mol}$ or $\mathrm{MJ} / \mathrm{mol})$ \\
\hline$E_{\mathrm{cw}}$ & total cooling duty (kWh) \\
\hline$E_{\mathrm{ST}}$ & total energy from hydrogen storage subsystem (kWh) \\
\hline$F$ & process stream flowrate $(\mathrm{kg} / \mathrm{h})$ \\
\hline$f^{\mathrm{CR}}$ & capital recovery factor \\
\hline$f_{i}$ & fraction of $i$ source in renewable power generation \\
\hline$f_{\mathrm{m}}$ & material correction factor for pressure vessel \\
\hline$f_{\mathrm{p}}$ & pressure correction factor for pressure vessel \\
\hline$f_{\mathrm{L}}^{\mathrm{RE}}$ & renewable penetration in a load $(\%)$ \\
\hline$k$ & kinetic constant \\
\hline$K$ & pre-exponential factor in reaction kinetics \\
\hline$L^{k}$ & storage holdup level of subsystem $k$ (kg or $\mathrm{kWh})$ \\
\hline$L_{\max }^{k}$ & maximum storage capacity of subsystem $k$ ( $\mathrm{kg}$ or $\mathrm{kWh})$ \\
\hline$M_{\mathrm{W}}$ & molecular weight $(\mathrm{kg} / \mathrm{kmol})$ \\
\hline$n$ & life of a unit (years) \\
\hline$N$ & total hours in an operational year, i.e., $8760 \mathrm{~h}$ \\
\hline$P$ & pressure (bar) \\
\hline$P_{\text {in }}$ & supply of electrical power at system inlet $(\mathrm{kW})$ \\
\hline$\overline{P_{\mathrm{L}}}$ & load of the methanol process $(\mathrm{kW})$ \\
\hline$P_{\text {out }}$ & curtailed electrical power at system outlet $(\mathrm{kW})$ \\
\hline$P_{\mathrm{S}}$ & generated solar power $(\mathrm{kW})$ \\
\hline$P_{\mathrm{W}}$ & generated wind power $(\mathrm{kW})$ \\
\hline$r$ & discount rate, taken as $8 \%$ \\
\hline$t$ & time $(h)$ \\
\hline$T$ & temperature $\left({ }^{\circ} \mathrm{C}\right.$ or $\left.\mathrm{K}\right)$ \\
\hline$x_{j}^{k}$ & consumption of utility $j$ in subsystem $k(\mathrm{~kW})$ \\
\hline
\end{tabular}




\section{Indices}

renewable power provision factor

efficiency of refrigeration cycle

hourly baseline extent of hydrogenation reaction $(\mathrm{kmol} / \mathrm{h})$

hourly extent of reaction $(\mathrm{kmol} / \mathrm{h})$

density of a fluid $\left(\mathrm{kg} / \mathrm{m}^{3}\right)$

fraction of the maximum operation load

lower bound of the operation envelope of SYN

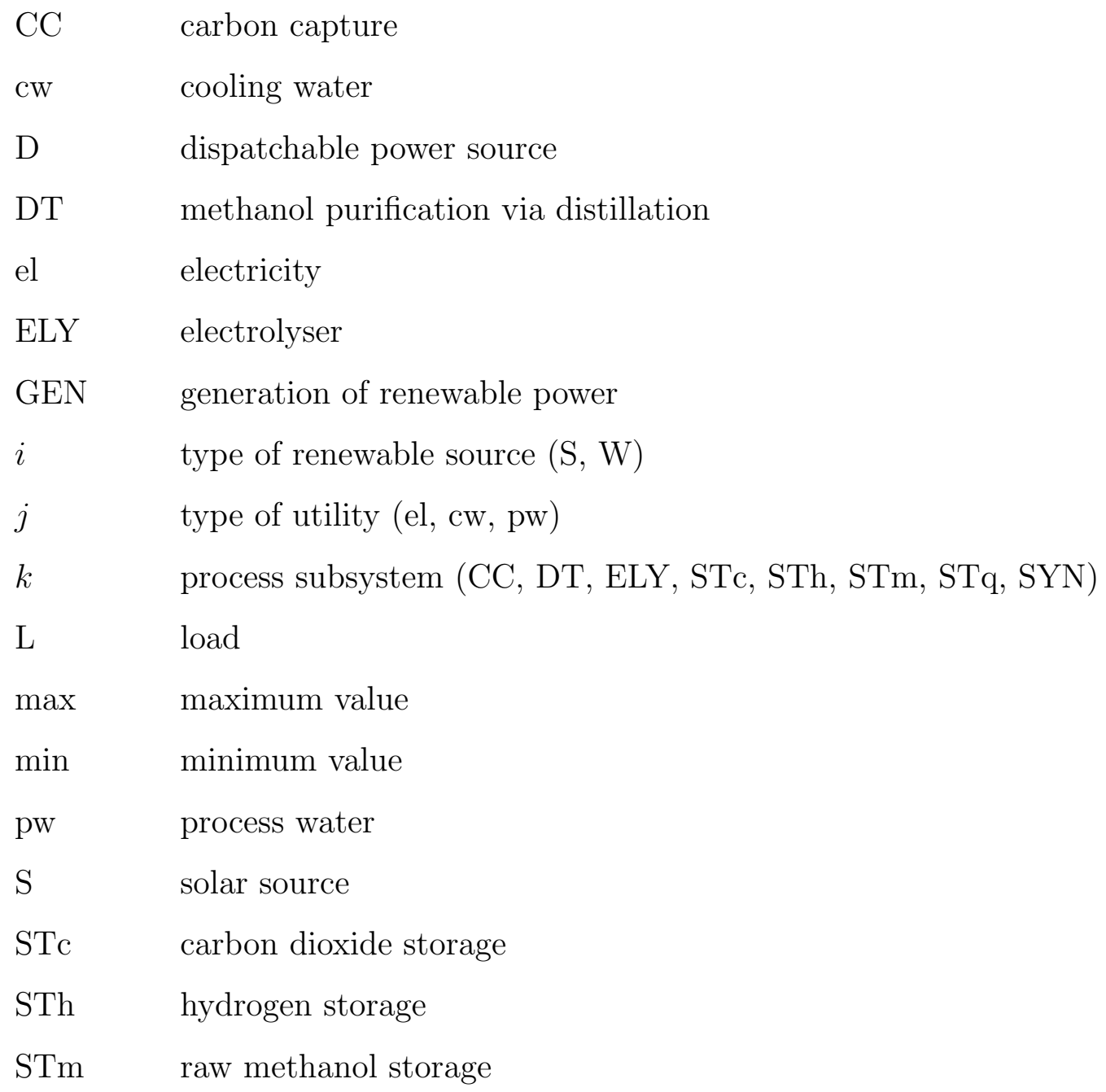


STq intermediate heat storage

SYN methanol synthesis loop

W wind source 
941

\section{References}

[1] J. L. Barton, "Electrification of the chemical industry," Science, vol. 368, no. 6496, pp. 1181-1182, 2020.

[2] International Renewable Energy Agency, "Electrification with renewables: Driving the transformation of energy services," report, 2019.

[3] Z. J. Schiffer and K. Manthiram, "Electrification and decarbonization of the chemical industry," Joule, vol. 1, no. 1, pp. 10-14, 2017.

[4] P.-H. Li and S. Pye, "Assessing the benefits of demand-side flexibility in residential and transport sectors from an integrated energy systems perspective," Applied Energy, vol. 228, pp. 965-979, 2018.

[5] D. Heide, M. Greiner, L. von Bremen, and C. Hoffmann, "Reduced storage and balancing needs in a fully renewable European power system with excess wind and solar power generation," Renewable Energy, vol. 36, no. 9, pp. 2515-2523, 2011.

[6] D. Heide, L. von Bremen, M. Greiner, C. Hoffmann, M. Speckmann, and S. Bofinger, "Seasonal optimal mix of wind and solar power in a future, highly renewable Europe," Renewable Energy, vol. 35, no. 11, pp. 2483-2489, 2010.

[7] R. Nayak-Luke, R. Bañares-Alcántara, and I. Wilkinson, “"Green” ammonia: Impact of renewable energy intermittency on plant sizing and levelized cost of ammonia," Industrial \& Engineering Chemistry Research, vol. 57, no. 43, pp. 14607-14616, 2018.

[8] M. Bos, S. Kersten, and D. Brilman, "Wind power to methanol: Renewable methanol production using electricity, electrolysis of water and $\mathrm{CO}_{2}$ 
air capture," Applied Energy, vol. 264, p. 114672, 2020.

[9] G. Hu, C. Chen, H. T. Lu, Y. Wu, C. Liu, L. Tao, Y. Men, G. He, and K. G. Li, "A review of technical advances, barriers and solutions in the power to hydrogen (P2H) roadmap," Engineering, 2020.

[10] M. G. Rasmussen, G. B. Andresen, and M. Greiner, "Storage and balancing synergies in a fully or highly renewable pan-European power system," Energy Policy, vol. 51, pp. 642-651, 2012.

[11] I. I. Cheema and U. Krewer, "Operating envelope of Haber-Bosch process design for power-to-ammonia," RSC Advances, vol. 8, pp. 34926-34936, 2018 .

[12] S. Matthischke, S. Roensch, and R. Güttel, "Start-up time and load range for the methanation of carbon dioxide in a fixed-bed recycle reactor," Industrial $\&$ Engineering Chemistry Research, vol. 57, no. 18, pp. 63916400, 2018.

[13] E. R. Morgan, Techno-Economic Feasibility Study of Ammonia Plants Powered by Offshore Wind. Thesis, University of Massachusetts Amherst, 2013.

[14] C. Hank, S. Gelpke, A. Schnabl, R. J. White, J. Full, N. Wiebe, T. Smolinka, A. Schaadt, H.-M. Henning, and C. Hebling, "Economics \& carbon dioxide avoidance cost of methanol production based on renewable hydrogen and recycled carbon dioxide - power-to-methanol," Sustainable Energy Fuels, vol. 2, pp. 1244-1261, 2018.

[15] T. B. Nguyen and E. Zondervan, "Methanol production from captured $\mathrm{CO}_{2}$ using hydrogenation and reforming technologies - environmental 
and economic evaluation," Journal of $\mathrm{CO}_{2}$ Utilization, vol. 34, pp. 1-11, 2019

[16] I. Yarulina, A. D. Chowdhury, F. Meirer, B. M. Weckhuysen, and J. Gascon, "Recent trends and fundamental insights in the methanolto-hydrocarbons process," Nature Catalysis, vol. 1, no. 6, pp. 398-411, 2018.

[17] A. Gonzalez-Garay, M. S. Frei, A. Al-Qahtani, C. Mondelli, G. GuillenGosalbez, and J. Perez-Ramirez, "Plant-to-planet analysis of $\mathrm{CO}_{2}$-based methanol processes," Energy \& Environmental Science, vol. 12, no. 12, pp. 3425-3436, 2019.

[18] C. Chen, Y. Lu, and R. Banares-Alcantara, "Direct and indirect electrification of chemical industry using methanol production as a case study," Applied Energy, vol. 243, pp. 71-90, 2019.

[19] B. H. Li, N. Zhang, and R. Smith, "Simulation and analysis of $\mathrm{CO}_{2}$ capture process with aqueous monoethanolamine solution," Applied Energy, vol. 161, pp. 707-717, 2016.

[20] E. S. Van-Dal and C. Bouallou, "Design and simulation of a methanol production plant from $\mathrm{CO}_{2}$ hydrogenation," Journal of Cleaner Production, vol. 57, pp. 38-45, 2013.

[21] M. Perez-Fortes, J. C. Schoneberger, A. Boulamanti, and E. Tzimas, "Methanol synthesis using captured $\mathrm{CO}_{2}$ as raw material: Technoeconomic and environmental assessment," Applied Energy, vol. 161, pp. 718-732, 2016.

[22] K. M. Vanden Bussche and G. F. Froment, "A steady-state kinetic model for methanol synthesis and the water gas shift reaction on a commercial 
$\mathrm{Cu} / \mathrm{ZnO} / \mathrm{Al}_{2} \mathrm{O}_{3}$ catalyst," Journal of Catalysis, vol. 161, no. 1, pp. 1-10, 1996.

[23] D. Mignard and C. Pritchard, "On the use of electrolytic hydrogen from variable renewable energies for the enhanced conversion of biomass to fuels," Chemical Engineering Research and Design, vol. 86, no. 5A, pp. 473-487, 2008.

[24] E. Carlson, "Don't gamble with physical properties for simulations," Chemical Engineering Progress, vol. 92, no. 10, pp. 35-46, 1996.

[25] B. Cañete, C. E. Gigola, and N. B. Brignole, "Synthesis gas processes for methanol production via $\mathrm{CH}_{4}$ reforming with $\mathrm{CO}_{2}, \mathrm{H}_{2} \mathrm{O}$, and $\mathrm{O}_{2}$," Industrial \& Engineering Chemistry Research, vol. 53, no. 17, pp. 71037112,2014

[26] E. Díez, P. Langston, G. Ovejero, and M. D. Romero, "Economic feasibility of heat pumps in distillation to reduce energy use," Applied Thermal Engineering, vol. 29, no. 5, pp. 1216-1223, 2009.

[27] S. S. Beerbühl, M. Fröhling, and F. Schultmann, "Combined scheduling and capacity planning of electricity-based ammonia production to integrate renewable energies," European Journal of Operational Research, vol. 241, no. 3, pp. 851-862, 2015.

[28] W. Kempton, F. M. Pimenta, D. E. Veron, and B. A. Colle, "Electric power from offshore wind via synoptic-scale interconnection," Proceedings of the National Academy of Sciences, vol. 107, no. 16, pp. 7240-7245, 2010.

[29] M. Matzen, M. Alhajji, and Y. Demirel, "Chemical storage of wind energy by renewable methanol production: Feasibility analysis using a 
multi-criteria decision matrix," Energy, vol. 93, pp. 343-353, 2015.

[30] Vestas Wind Systems, "General specification for V90 - 3.0 MW: $60 \mathrm{~Hz}$ variable speed turbine," report, 2004

[31] D. Steward, "Scenario development and analysis of hydrogen as a largescale energy storage medium," report, National Renewable Energy Laboratory, 2009.

[32] C. Zhang, K.-W. Jun, R. Gao, G. Kwak, and H.-G. Park, "Carbon dioxide utilization in a gas-to-methanol process combined with $\mathrm{CO}_{2} /$ steam-mixed reforming: Techno-economic analysis," Fuel, vol. 190, pp. 303-311, 2017.

[33] J. M. Douglas, Conceptual design of chemical processes. McGraw-Hill Book Company, 1988.

[34] I. Sarbu and C. Sebarchievici, "A comprehensive review of thermal energy storage," Sustainability, vol. 10, no. 1, pp. 191-223, 2018.

[35] C. Chen, "Using dispatchable energy price as a tool to predict and influence the renewable penetration in chemical production," in Proceedings of the 23rd Conference on Process Integration, Modelling and Optimisation for Energy Saving and Pollution Reduction, 2020.

[36] A. Varone and M. Ferrari, "Power to liquid and power to gas: An option for the german energiewende," Renewable and Sustainable Energy Reviews, vol. 45, pp. 207-218, 2015.

[37] US Energy Information Administration, "Electric power monthly with data for January 2020," report, 2020.

[38] J. Armijo and C. Philibert, "Flexible production of green hydrogen and ammonia from variable solar and wind energy: Case study of Chile and 
Argentina," International Journal of Hydrogen Energy, vol. 45, no. 3, pp. 1541-1558, 2020.

[39] C. Budischak, D. Sewell, H. Thomson, L. Mach, D. E. Veron, and W. Kempton, "Cost-minimized combinations of wind power, solar power and electrochemical storage, powering the grid up to $99.9 \%$ of the time," Journal of Power Sources, vol. 225, pp. 60-74, 2013.

[40] D. Fiaschi, G. Manfrida, R. Secchi, and D. Tempesti, "A versatile system for offshore energy conversion including diversified storage," Energy, vol. 48, no. 1, pp. 566-576, 2012.

[41] M. Z. Jacobson and M. A. Delucchi, "Providing all global energy with wind, water, and solar power, Part I: Technologies, energy resources, quantities and areas of infrastructure, and materials," Energy Policy, vol. 39, no. 3, pp. 1154-1169, 2011.

[42] M. A. Delucchi and M. Z. Jacobson, "Providing all global energy with wind, water, and solar power, Part II: Reliability, system and transmission costs, and policies," Energy Policy, vol. 39, no. 3, pp. 1170-1190, 2011.

[43] J. Miah, A. Griffiths, R. McNeill, I. Poonaji, R. Martin, A. Yang, and S. Morse, "Heat integration in processes with diverse production lines: A comprehensive framework and an application in food industry," Applied Energy, vol. 132, pp. 452-464, 2014.

[44] Z. Geng, Y. Zhang, C. Li, Y. Han, Y. Cui, and B. Yu, "Energy optimization and prediction modeling of petrochemical industries: An improved convolutional neural network based on cross-feature," Energy, vol. 194, p. $116851,2020$. 
[45] Z. Wang, Y. Han, C. Li, Z. Geng, and J. Fan, "Input-output networks considering graphlet-based analysis for production optimization: Application in ethylene plants," Journal of Cleaner Production, vol. 278, p. $123955,2021$.

[46] Aspen Technology, Inc., "Rate-based model of the $\mathrm{CO}_{2}$ capture process by MEA using Aspen Plus," dataset, 2012.

[47] E. Sanchez-Fernandez, E. L. V. Goetheer, G. Manzolini, E. Macchi, S. Rezvani, and T. J. H. Vlugt, "Thermodynamic assessment of amine based $\mathrm{CO}_{2}$ capture technologies in power plants based on European Benchmarking Task Force methodology," Fuel, vol. 129, pp. 318-329, 2014.

[48] C. Zhang, K.-W. Jun, R. Gao, Y.-J. Lee, and S. C. Kang, "Efficient utilization of carbon dioxide in gas-to-liquids process: Process simulation and techno-economic analysis," Fuel, vol. 157, pp. 285-291, 2015.

[49] M. S. Peter and K. D. Timmerhaus, Plant design and economics for chemical engineers. McGraw Hill, 1991.

[50] B. Cañete, C. E. Gigola, and N. B. Brignole, "Enhancing the potential of methane combined reforming for methanol production via partial $\mathrm{CO}_{2}$ hydrogenation," Industrial \& Engineering Chemistry Research, vol. 56, no. 22, pp. 6480-6492, 2017.

[51] D. Gielen, F. Boshell, R. Gorini, J. Kiruja, P. Komor, T. Masuyama, and B. Parthan, "Renewable power generation costs in 2019," report, International Renewable Energy Agency, 2019.

[52] S. M. Saba, M. Müller, M. Robinius, and D. Stolten, "The investment costs of electrolysis - a comparison of cost studies from the past 30 years," 
International Journal of Hydrogen Energy, vol. 43, no. 3, pp. 1209-1223, 2018 .

[53] R. Scataglini, A. Mayyas, M. Wei, S. H. Chan, T. Lipman, D. Gosselin, A. D'Alessio, H. Breunig, W. G. Colella, and B. D. James, "A total cost of ownership model for solid oxide fuel cells in combined heat and power and power-only applications," report, Ernest Orlando Lawrence Berkeley National Laboratory, 2015.

[54] A. Hauer, "Thermal energy storage," report, International Renewable Energy Agency, 2013.

[55] D. Pauschert, "Study of equipment prices in the power sector," tech. rep., Energy Sector Management Assistance Program, 2009.

[56] A. Buttler and H. Spliethoff, "Current status of water electrolysis for energy storage, grid balancing and sector coupling via power-to-gas and power-to-liquids: A review," Renewable and Sustainable Energy Reviews, vol. 82 , pp. 2440-2454, 2018. 


\section{Power-to-methanol: The role of process flexi-}

\section{bility in the integration of variable renewable} energy into chemical production

Chao Chen ${ }^{1}$, Aidong Yang ${ }^{1, *}$

${ }^{1}$ Department of Engineering Science, University of Oxford, Parks Road, Oxford OX1 3PJ, UK

Key words: process flexibility, methanol, renewable source intermittency, energy storage, conceptual design, model-based optimisation

\section{Supplementary Information}

\section{Carbon capture process}

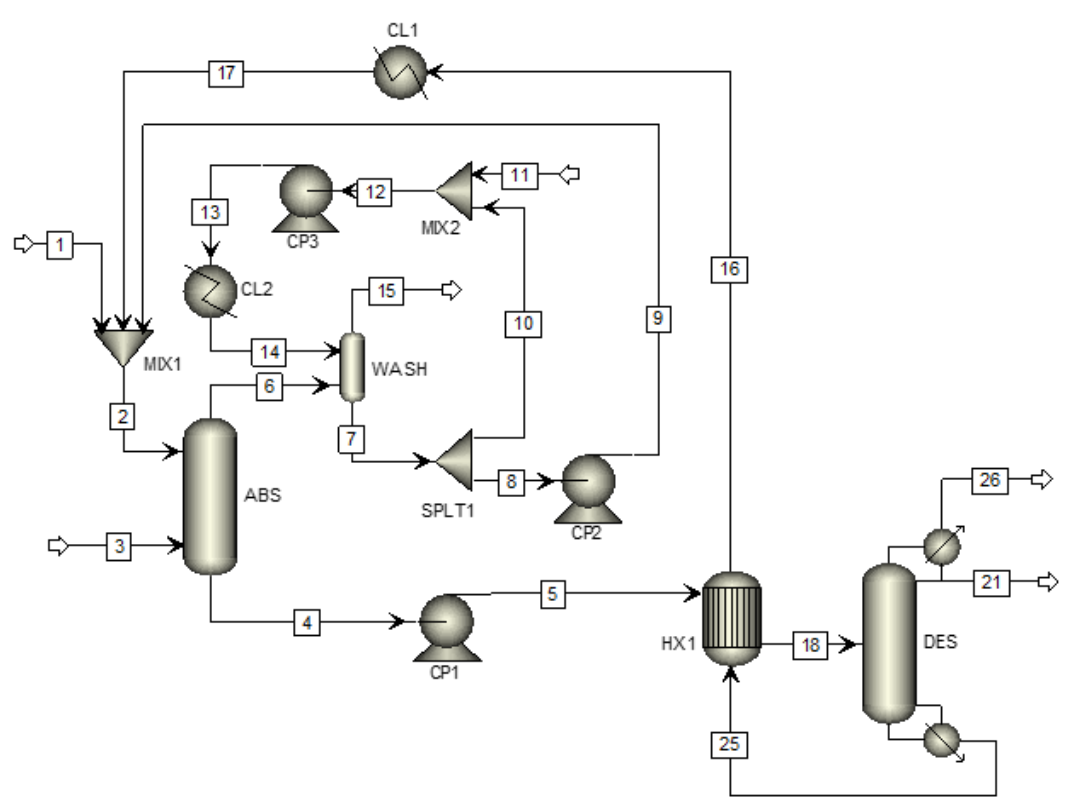

Figure 5. Process flow diagram of the carbon capture subsystem simulated in Aspen Plus. 
Table 6. Key streams conditions for the carbon capture process. Note that the trace amounts of other ions such as hydroxide ion and carbonate are not shown in this table.

\begin{tabular}{|c|c|c|c|c|c|c|c|c|}
\hline Stream & 1 & 2 & 4 & 15 & 18 & 21 & 25 & 26 \\
\hline$T\left({ }^{\circ} \mathrm{C}\right)$ & 40.0 & 18.0 & 53.3 & 43.9 & 112.9 & 18.0 & 119.3 & 18.0 \\
\hline$P$ (bar) & 2.0 & 2.0 & 1.0 & 1.0 & 2.9 & 2.00 & 2.00 & 2.0 \\
\hline$F(\mathrm{~kg} / \mathrm{h})$ & 82.1 & $3.4 \times 10^{6}$ & $3.4 \times 10^{6}$ & $1.1 \times 10^{6}$ & $3.4 \times 10^{6}$ & $3.3 \times 10^{4}$ & $3.3 \times 10^{6}$ & $8.1 \times 10^{4}$ \\
\hline \multicolumn{9}{|c|}{ Composition (wt\%) } \\
\hline MEA & 100.0 & 13.0 & 6.2 & 0.0 & 7.9 & 0.0 & 13.9 & 0.0 \\
\hline $\mathrm{H}_{2} \mathrm{O}$ & 0.0 & 67.7 & 66.1 & 7.6 & 65.6 & 99.5 & 67.2 & 0.4 \\
\hline $\mathrm{CO}_{2}$ & 0.0 & 0.0 & 0.0 & 1.8 & 0.0 & 0.3 & 0.0 & 99.4 \\
\hline $\mathrm{N}_{2}$ & 0.0 & 0.0 & 0.0 & 79.8 & 0.0 & 0.0 & 0.0 & 0.1 \\
\hline $\mathrm{O}_{2}$ & 0.0 & 0.0 & 0.0 & 10.8 & 0.0 & 0.0 & 0.0 & 0.0 \\
\hline $\mathrm{MEAH}^{+}$ & 0.0 & 7.4 & 10.5 & 0.0 & 10.4 & 0.1 & 7.3 & 0.0 \\
\hline $\mathrm{MEACOO}^{-}$ & 0.0 & 11.6 & 16.9 & 0.0 & 14.1 & 0.0 & 10.7 & 0.0 \\
\hline
\end{tabular}

Table 7. Composition of the flue gas (Stream 3 in Supplementary Figure 5) fed to the carbon capture process. Data obtained from Ref. [46].

\begin{tabular}{ll}
\hline \hline Component & wt\% \\
\hline $\mathrm{N}_{2}$ & 74.3 \\
$\mathrm{O}_{2}$ & 10.1 \\
$\mathrm{CO}_{2}$ & 8.5 \\
$\mathrm{H}_{2} \mathrm{O}$ & 7.1 \\
\hline \hline
\end{tabular}

Table 8. Pre-exponential factor $(K)$ and activation energy $\left(E_{\mathrm{a}}\right)$ in the rate-controlled reactions for the carbon capture process. The kinetic parameters for the absorber and the desorber are the same unless otherwise specified. Data obtained from Ref. [47].

\begin{tabular}{lll}
\hline \hline & $K$ & $E_{\mathrm{a}}(\mathrm{MJ} / \mathrm{mol})$ \\
\hline Reaction 6 & $1.33 \times 10^{17}$ & 55.5 \\
Reaction 7 & $6.63 \times 10^{16}$ & 107.4 \\
Reaction 8 & $3.02 \times 10^{14}$ & 41.3 \\
Reaction 9 (absorber) & $5.52 \times 10^{23}$ & 69.2 \\
Reaction 9 (desorber) & $6.50 \times 10^{27}$ & 95.4 \\
\hline \hline
\end{tabular}




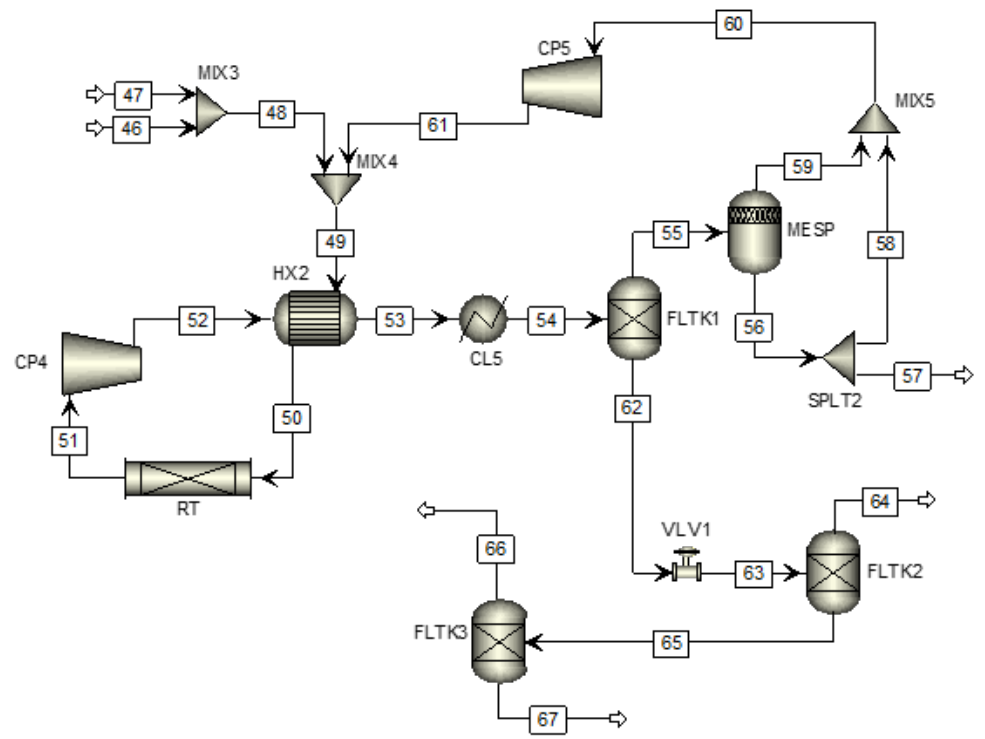

Figure 6. Process flow diagram of the $\mathrm{CO}_{2}$ hydrogenation subsystem simulated in Aspen Plus.

Table 9. Key streams conditions for the $\mathrm{CO}_{2}$ hydrogenation process.

\begin{tabular}{lllllllll}
\hline \hline Stream & 49 & 50 & 51 & 53 & 55 & 62 & 65 & 67 \\
\hline$T\left({ }^{\circ} \mathrm{C}\right)$ & 74.7 & 255.0 & 255.0 & 125.4 & 40.0 & 40.0 & 35.5 & 35.5 \\
$P(\mathrm{bar})$ & 70.0 & 70.0 & 70.0 & 74.0 & 70.0 & 70.0 & 1.1 & 1.1 \\
$F(\mathrm{~kg} / \mathrm{h})$ & 239,755 & 239,755 & 239,755 & 239,755 & 151,622 & 88,141 & 80,442 & 79,224 \\
& & & & & & & & \\
Composition & $(\mathrm{wt} \%)$ & & & & & & & \\
Methanol & 0.9 & 0.9 & 22.3 & 22.3 & 1.5 & 58.1 & 62.5 & 63.4 \\
$\mathrm{H}_{2} \mathrm{O}$ & 0.1 & 0.1 & 12.3 & 12.3 & 0.2 & 33.0 & 36.0 & 36.6 \\
$\mathrm{H}_{2}$ & 25.0 & 25.0 & 21.0 & 21.0 & 33.2 & 0.1 & 0.0 & 0.0 \\
$\mathrm{CO}_{2}$ & 69.2 & 69.2 & 39.5 & 39.5 & 57.4 & 8.8 & 1.5 & 0.0 \\
$\mathrm{CO}$ & 4.7 & 4.7 & 4.9 & 4.9 & 7.7 & 0.1 & 0.0 & 0.0 \\
\hline \hline
\end{tabular}


Table 10. Reaction kinetic constants and parameters for the methanol synthesis kinetic model. Data obtained and rearranged from Ref. [22].

\begin{tabular}{llll}
\hline \hline Reaction Constant & $E_{\mathrm{a} i}(\mathrm{~J} / \mathrm{mol})$ & $A_{i}$ & $B_{i}(\mathrm{~K})$ \\
\hline$k_{1}$ & $-40,000$ & -29.870 & $4,811.16$ \\
$k_{2}$ & - & 8.147 & 0 \\
$k_{3}$ & $-17,197$ & -6.452 & $2,068.44$ \\
$k_{4}$ & $-124,119$ & -23.440 & $14,928.92$ \\
$k_{5}$ & 98,084 & 4.804 & $-11,797.45$ \\
$k_{6}$ & 18,705 & 17.550 & $-2,249.80$ \\
$k_{7}$ & 58,393 & 0.131 & $-7,023.50$ \\
\hline \hline
\end{tabular}


 \\ Methanol distillation process}

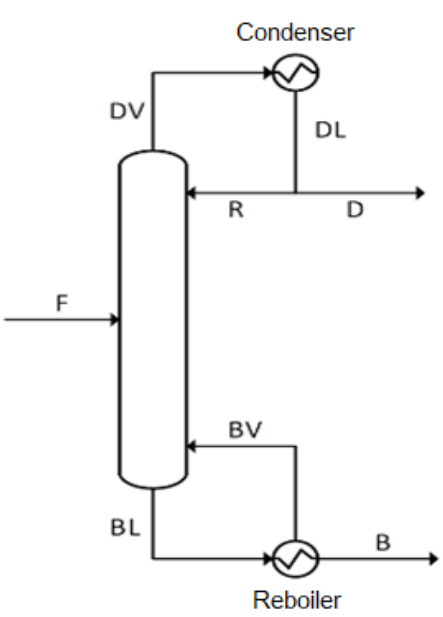

(A)

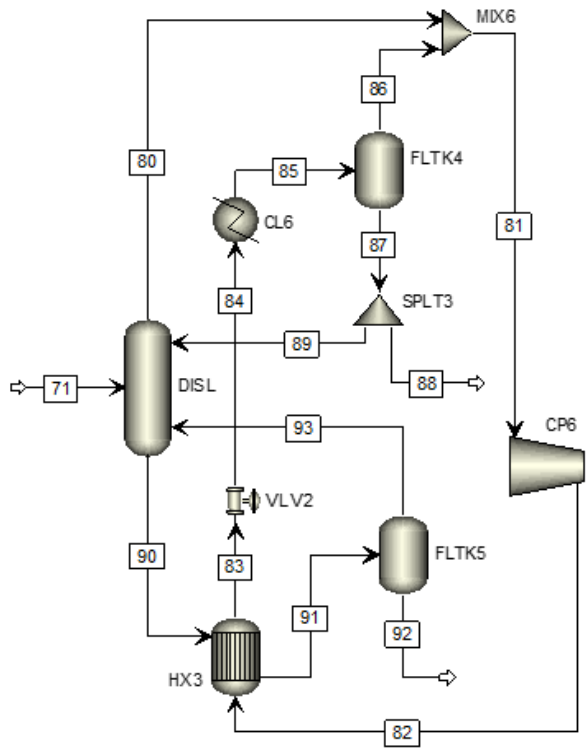

(B)

Figure 7. (A) Schematic diagram of a traditional distillation column. (B) Process flow diagram of the distillation subsystem modified with a design of mechanical vapour recompression.

Table 11. Physical meaning of the key streams in Figure 7.

\begin{tabular}{lll}
\hline \hline$(\mathrm{A})$ & $(\mathrm{B})$ & Description \\
\hline F & 71 & Feed to the distillation column \\
D & 88 & Distillate product \\
B & 92 & Bottom product \\
R & 89 & Reflux to the second stage \\
DV & 80 & Second stage vapour \\
DL & 87 & First stage liquid \\
BV & 93 & Boilup to the penultimate stage \\
BL & 90 & Penultimate stage liquid \\
\hline \hline
\end{tabular}


Table 12. Streams conditions for the distillation process.

\begin{tabular}{llllll}
\hline \hline \multirow{2}{*}{ Stream } & $T\left({ }^{\circ} \mathrm{C}\right)$ & $P($ bar $)$ & $F(\mathrm{~kg} / \mathrm{h})$ & \multicolumn{2}{c}{ Composition $(\mathrm{wt} \%)$} \\
\cline { 5 - 6 } & & & & Methanol & $\mathrm{H}_{2} \mathrm{O}$ \\
\hline 80 & 66.8 & 1.1 & 95,326 & 99.8 & 0.2 \\
81 & 66.8 & 1.1 & 106,854 & 99.8 & 0.2 \\
82 & 188.2 & 4.8 & 106,854 & 99.8 & 0.2 \\
83 & 110.0 & 4.8 & 106,854 & 99.8 & 0.2 \\
84 & 66.7 & 1.1 & 106,854 & 99.8 & 0.2 \\
85 & 66.7 & 1.1 & 106,854 & 99.8 & 0.2 \\
86 & 66.7 & 1.1 & 11,528 & 99.9 & 0.1 \\
87 & 66.7 & 1.1 & 95,326 & 99.8 & 0.2 \\
88 & 66.7 & 1.1 & 49,649 & 99.8 & 0.2 \\
89 & 66.7 & 1.1 & 45,677 & 99.8 & 0.2 \\
90 & 93.5 & 1.1 & 86,215 & 10.8 & 89.2 \\
91 & 100.0 & 1.1 & 86,215 & 10.8 & 89.2 \\
92 & 100.0 & 1.1 & 29,574 & 2.3 & 97.7 \\
93 & 100.0 & 1.1 & 56,641 & 15.1 & 84.9 \\
\hline \hline
\end{tabular}

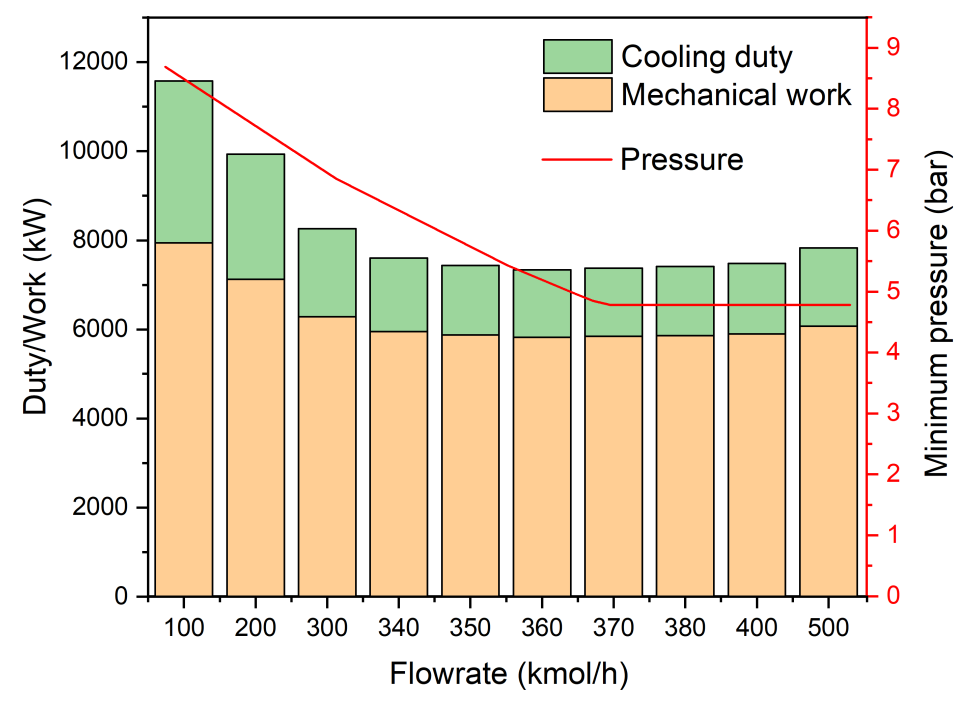

Figure 8. Requirement of mechanical work, cooling duty and minimum target pressure with respect to the flowrate of the working fluid. 
Table 13. Utility and cost for the main equipments shown in Figure 1. Note that the electrical power consumed by DES comprises electrical heating by the reboiler and mechanical work by the refrigerator (refg.) of the condenser. All of the equipment cost (except the catalytic reactor) is obtained from Aspen Process Economic Analyser directly after process simulations. The cost of the catalytic reactor (RT) is estimated via the six-tenths factor rule based on Ref. [48].

\begin{tabular}{|c|c|c|c|c|}
\hline & $\begin{array}{l}\text { Mechanical } \\
\text { work }(\mathrm{kW})\end{array}$ & $\begin{array}{l}\text { Electrical } \\
\text { heating }(\mathrm{kW})\end{array}$ & $\begin{array}{l}\text { Cooling water } \\
\text { duty }(\mathrm{kW})\end{array}$ & Equipment cost (\$) \\
\hline \multicolumn{5}{|c|}{ CC subsystem } \\
\hline CL1 & 0.0 & 0.0 & $-62,717.4$ & 541,400 \\
\hline CL2 & 0.0 & 0.0 & $-1,762.8$ & 28,000 \\
\hline $\mathrm{CP} 1$ & 578.5 & 0.0 & 0.0 & 116,400 \\
\hline $\mathrm{CP} 2$ & 3.5 & 0.0 & 0.0 & 5,700 \\
\hline CP3 & 50.2 & 0.0 & 0.0 & 15,500 \\
\hline HX1 & 0.0 & 0.0 & 0.0 & $5,982,200$ \\
\hline ABS & 0.0 & 0.0 & 0.0 & $33,384,600$ \\
\hline DES & 0.0 & $117,111.4$ & $-50,745.2$ & $12,502,180$ \\
\hline DES (refg.) & 558.9 & 0.0 & 0.0 & - \\
\hline \multicolumn{5}{|c|}{ DT subsystem } \\
\hline DISL & 0.0 & 0.0 & 0.0 & 510,300 \\
\hline HX3 & 0.0 & 0.0 & 0.0 & 479,400 \\
\hline FLTK4 & 0.0 & 0.0 & 0.0 & 31,700 \\
\hline FLTK5 & 0.0 & 0.0 & 0.0 & 34,400 \\
\hline CL6 & 0.0 & 0.0 & $-1,515.6$ & 18,900 \\
\hline $\mathrm{CP} 6$ & $5,828.3$ & 0.0 & 0.0 & $13,899,400$ \\
\hline \multicolumn{5}{|c|}{ SYN subsystem } \\
\hline MCP1 & $7,099.6$ & 0.0 & $-4,974.8$ & $5,004,100$ \\
\hline MCP2 & $24,997.8$ & 0.0 & $-16,186.1$ & $36,512,500$ \\
\hline CL5 & 0.0 & 0.0 & $-45,045.5$ & 371,100 \\
\hline HX2 & 0.0 & 0.0 & 0.0 & $2,970,800$ \\
\hline $\mathrm{RT}$ & 0.0 & 0.0 & $-26,017.6$ & $15,441,003$ \\
\hline MSEP & 0.0 & 0.0 & 0.0 & 112,800 \\
\hline FLTK1 & 0.0 & 0.0 & 0.0 & 102,300 \\
\hline FLTK2 & 0.0 & 0.0 & 0.0 & 29,000 \\
\hline FLTK3 & 0.0 & 0.0 & 0.0 & 29,000 \\
\hline $\mathrm{CP} 4$ & 2807.4 & 0.0 & 0.0 & $1,375,400$ \\
\hline CP5 & 8.9 & 0.0 & 0.0 & 702,700 \\
\hline
\end{tabular}




\section{Renewable data}
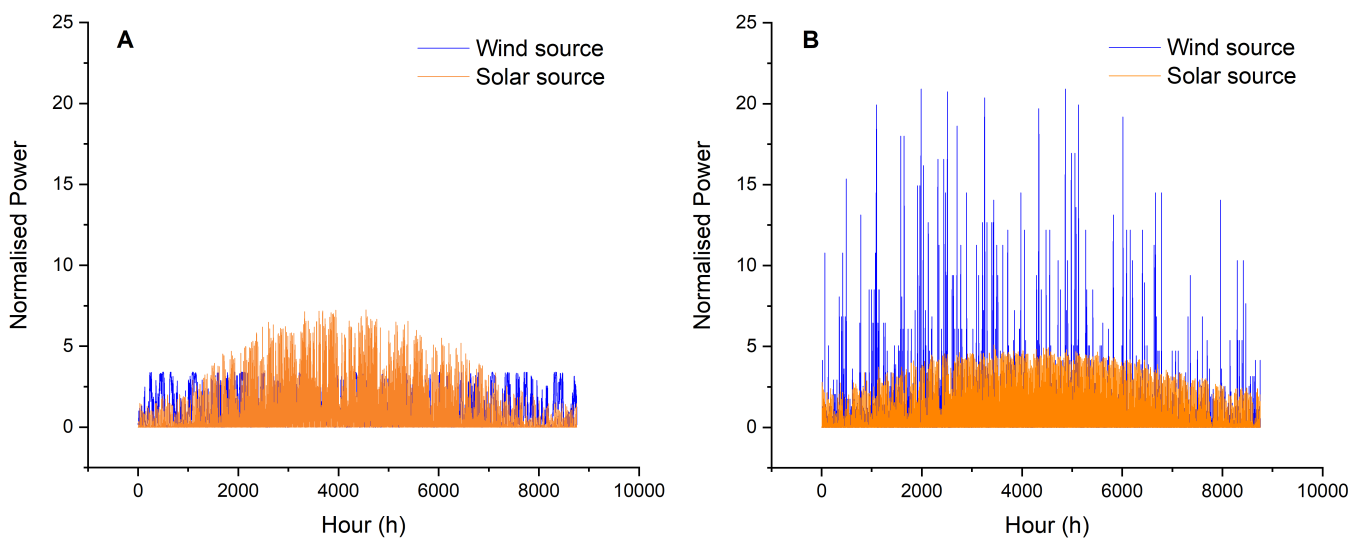

Figure 9. Year-round availability of wind and solar source for (A) Norderney, Germany and (B) Kramer Junction, US. Each series is shown in 1-hour resolution and normalised by the respective yearly mean value. Data are obtained from Meteonorm, a meteorological database.

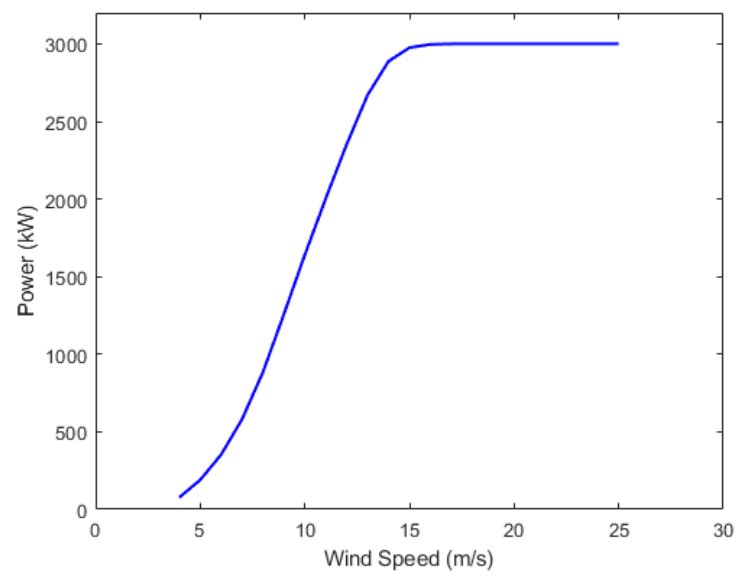

Figure 10. Power curve for V90 3.0 MW turbine. Air density is assumed to be 1.225 $\mathrm{kg} / \mathrm{m}^{3}$. Data obtained from Ref. [30]. 


\section{Variables and constant parameters}

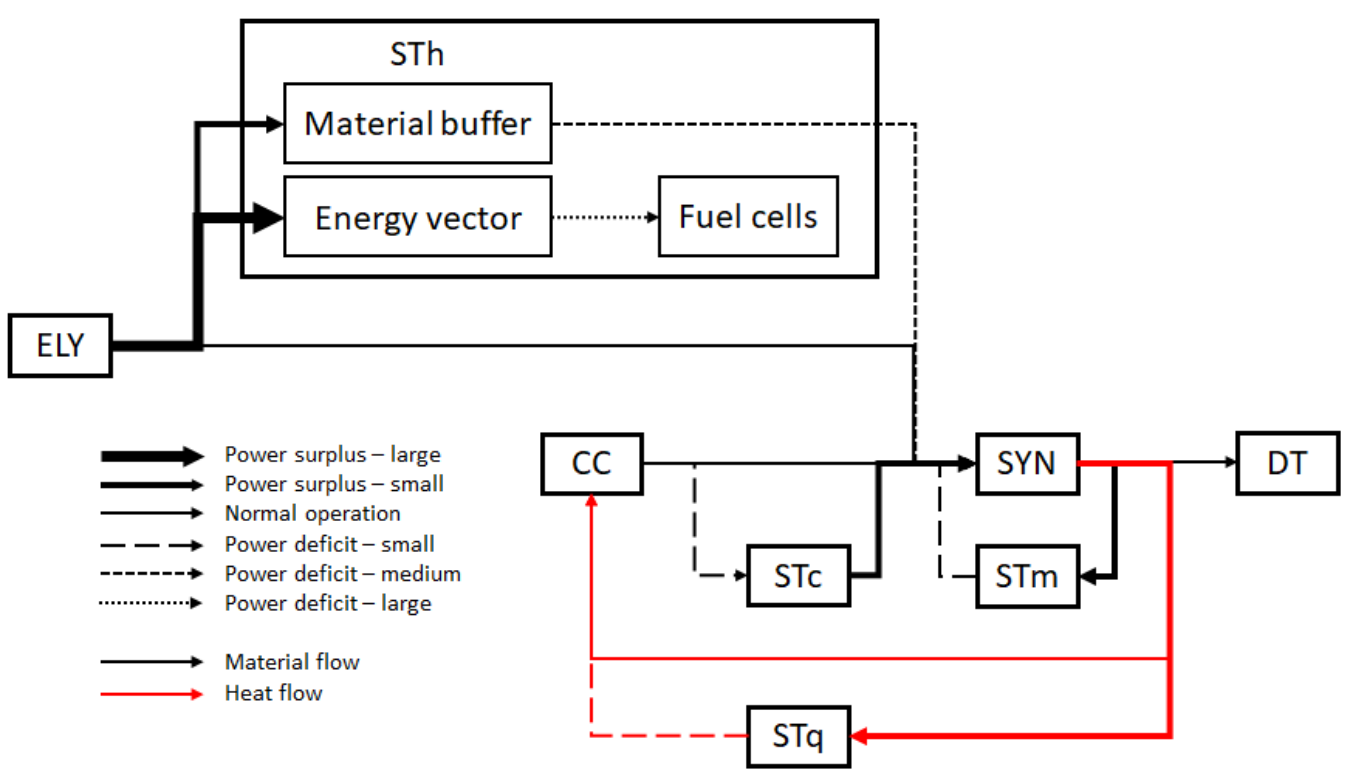

Figure 11. Schematic illustration of a simplified operation policy on material and heat flow.

Table 14. Key decision variables and their descriptions.

\begin{tabular}{llll}
\hline \hline & Unit & Domain & Description \\
\hline$F_{32}$ & $\mathrm{~kg} / \mathrm{h}$ & Time & $\mathrm{H}_{2}$ storage charging schedule \\
$F_{35}$ & $\mathrm{~kg} / \mathrm{h}$ & Time & $\mathrm{H}_{2}$ fuel cells output schedule \\
$F_{41}$ & $\mathrm{~kg} / \mathrm{h}$ & Time & $\mathrm{CO}_{2}$ storage charging schedule \\
$F_{68}$ & $\mathrm{~kg} / \mathrm{h}$ & Time & Raw methanol storage charging schedule \\
$\dot{Q}_{3}$ & $\mathrm{~kW}$ & Time & heat storage charging schedule \\
$\dot{Q}_{4}$ & $\mathrm{~kW}$ & Time & heat storage discharging schedule \\
$P_{\mathrm{D}}$ & $\mathrm{kW}$ & Time & dispatchable power use \\
$\phi$ & - & Time & load fraction an operation unit \\
$f_{\mathrm{W}}$ & - & singular & wind fraction in renewable power generation \\
$\gamma$ & - & singular & excess generation of the renewable power \\
$x_{\mathrm{el}, \max }^{\mathrm{ELY}}$ & $\mathrm{kW}$ & singular & maximum size of the electrolysers \\
$\dot{\xi}_{\max }$ & $\mathrm{kmol} / \mathrm{h}$ & singular & maximum size of the methanol reactor \\
\hline \hline & & &
\end{tabular}


Table 15. Summary of constant parameters.

\begin{tabular}{|c|c|c|c|}
\hline & Value & Unit & Description \\
\hline \multicolumn{3}{|c|}{ Process coefficient } & \\
\hline$a_{1}^{\mathrm{STh}}$ & 3.03 & $\mathrm{kWh} / \mathrm{kg}$ & specific electricity consumption of MCP3 \\
\hline$a_{2}^{\mathrm{STh}}$ & 1.07 & $\mathrm{kWh} / \mathrm{kg}$ & specific electricity consumption of HT2 \\
\hline$a_{3}^{\mathrm{STh}}$ & 22.28 & $\mathrm{kWh} / \mathrm{kg}$ & specific electricity output of FC \\
\hline$a_{4}^{\mathrm{STh}}$ & 0.21 & $\mathrm{kWh} / \mathrm{kg}$ & specific electricity output of TUB \\
\hline$a_{5}^{\mathrm{S} T h}$ & 2.99 & $\mathrm{kWh} / \mathrm{kg}$ & specific cooling duty of MCP3 \\
\hline$a_{1}^{\mathrm{SYN}}$ & $7,099.64$ & $\mathrm{~kW}$ & electricity consumption of MCP1 \\
\hline$a_{2}^{\mathrm{S} Y \mathrm{~N}}$ & 2.55 & $\mathrm{kWh} / \mathrm{kg}$ & specific electricity consumption of MCP2 \\
\hline$a_{3}^{\mathrm{SYN}}$ & 1.76 & $\mathrm{kWh} / \mathrm{kmol}$ & electricity coefficient for SYN recycle loop \\
\hline$a_{4}^{\stackrel{S}{S} Y N}$ & $4,974.81$ & $\mathrm{~kW}$ & cooling duty of MCP1 \\
\hline$a_{5}^{\stackrel{S}{S} \mathrm{YN}}$ & 1.65 & $\mathrm{kWh} / \mathrm{kg}$ & specific cooling duty of MCP2 \\
\hline$a_{6}^{\mathrm{S} Y \mathrm{~N}}$ & 28.16 & $\mathrm{~kW} / \mathrm{kmol}$ & cooling duty coefficient for SYN recycle loop \\
\hline$a_{1}^{\mathrm{STc}}$ & 0.05 & $\mathrm{kWh} / \mathrm{kg}$ & specific electricity consumption of HT3 \\
\hline$a_{2}^{\mathrm{STC}}$ & 0.05 & $\mathrm{kWh} / \mathrm{kg}$ & specific cooling duty of CL4 \\
\hline$b_{\mathrm{h}}$ & 6.12 & $\mathrm{~kg} / \mathrm{kmol}$ & coefficient for hydrogen flowrate to SYN \\
\hline$b_{\mathrm{m}}$ & 8.09 & - & coefficient for raw methanol flowrate to DT \\
\hline$b_{\mathrm{c}}$ & 8.31 & - & coefficient for carbon dioxide flowrate to SYN \\
\hline$b_{\mathrm{q}}$ & 16.26 & $\mathrm{kWh} / \mathrm{kmol}$ & specific heat output of RT \\
\hline \multicolumn{3}{|c|}{ Process stream } & \\
\hline$F_{26}$ & $81,426.93$ & $\mathrm{~kg} / \mathrm{h}$ & flowrate of carbon dioxide generated from CC \\
\hline$F_{71}$ & $79,222.96$ & $\mathrm{~kg} / \mathrm{h}$ & flowrate of raw methanol feed to DT \\
\hline$F_{88}$ & $49,648.94$ & $\mathrm{~kg} / \mathrm{h}$ & flowrate of methanol product from DT \\
\hline$F_{92}$ & $29,574.02$ & $\mathrm{~kg} / \mathrm{h}$ & flowrate of waste water from DT \\
\hline$\rho_{42}$ & 647.56 & $\mathrm{~kg} / \mathrm{m}^{3}$ & density of stored carbon dioxide stream in STc \\
\hline$\rho_{67}$ & 838.09 & $\mathrm{~kg} / \mathrm{m}^{3}$ & density of stored raw methanol stream in STm \\
\hline \multicolumn{3}{|c|}{ Utility parameter } & \\
\hline$x_{\mathrm{el}, 0}^{\mathrm{CC}}$ & $92,290.68$ & $\mathrm{~kW}$ & electricity required by $\mathrm{CC}$ excluding heat \\
\hline$x_{\mathrm{el}}^{\mathrm{DT}}$ & $5,828.30$ & $\mathrm{~kW}$ & electricity required by DT \\
\hline$x_{\mathrm{cw}}^{\mathrm{CC}}$ & $115,225.43$ & $\mathrm{~kW}$ & cooling duty in $\mathrm{CC}$ \\
\hline$x_{\mathrm{cw}}^{\mathrm{DT}}$ & $1,515.63$ & $\mathrm{~kW}$ & cooling duty in DT \\
\hline$\dot{Q}_{5}$ & $26,011.88$ & $\mathrm{~kW}$ & process heat fed to $\mathrm{CC}$ \\
\hline \multicolumn{3}{|c|}{ Operation parameter } & \\
\hline$\dot{\xi}_{0}$ & $1,599.68$ & $\mathrm{kmol} / \mathrm{h}$ & hourly baseline extent of hydrogenation reaction \\
\hline$\phi_{\min }$ & 0.1 & - & minimum load of SYN \\
\hline$e_{\max }^{\mathrm{ELY}}$ & 55.7 & $\mathrm{kWh} / \mathrm{kg}$ & maximum specific energy requirement for eletrolyser \\
\hline$e_{\min }^{\mathrm{ELY}}$ & 39.4 & $\mathrm{kWh} / \mathrm{kg}$ & minimum specific energy requirement for eletrolyser \\
\hline
\end{tabular}




\section{Economic parameters}

\section{Note 1: Pressure vessel cost}

The cost approximation for pressure vessels is adopted from Douglas' method [33], which is based on empirical correlations. The cost function is rearranged into Eq. 77 :

$$
\text { Pressure Vessel Cost }=\left(\frac{\mathrm{M} \& \mathrm{~S}}{280}\right) 101.9 D^{1.07} H^{0.82}\left(2.18+2 f_{\mathrm{m}} f_{\mathrm{p}}\right)
$$

where $D$ and $H$ denote the diameter and height of the vessel, respectively, $f_{\mathrm{m}}$ and $f_{\mathrm{p}}$ denote the correction factor for material and pressure, respectively, and $\mathrm{M} \& \mathrm{~S}$ denotes the Marshall and Swift Cost Index, taken as 1638. Material selection and values of the correction factors are tabulated in Table 16. Assuming an aspect ratio of 3:1, the annualised cost for STc and STm are rearranged and given by

$$
\begin{aligned}
C^{\mathrm{STc}} & =111.27 f^{\mathrm{CR}}\left(\frac{\mathrm{M} \& \mathrm{~S}}{280}\right)\left(\frac{L_{\max }^{\mathrm{STc}}}{\rho_{42}}\right)^{0.63} \\
C^{\mathrm{STm}} & =64.78 f^{\mathrm{CR}}\left(\frac{\mathrm{M} \& \mathrm{~S}}{280}\right)\left(\frac{L_{\max }^{\mathrm{STm}}}{\rho_{67}}\right)^{0.63}
\end{aligned}
$$

where $\rho_{42}$ and $\rho_{67}$ denote the density of the pressurised $\mathrm{CO}_{2}$ (Stream 42 in Figure 1) and the raw methanol (Stream 67), respectively. Since the maximum capacity of a pressure vessel is constrained, a linear cost function is derived from Eqs. 78 and 79 based on a maximum capacity of 200 tonne. This is justified by the fact that $L_{\max }^{\mathrm{STc}}$ and $L_{\max }^{\mathrm{STm}}$ are much larger than the capacity of a single vessel.

Table 16. Correction factors for pressure vessels.

\begin{tabular}{llllll}
\hline \hline & Material & $T\left({ }^{\circ} \mathrm{C}\right)$ & $P($ bar $)$ & $f_{\mathrm{m}}$ & $f_{\mathrm{p}}$ \\
\hline STc & carbon steel, solid & 29.3 & 71.0 & 1.00 & 2.50 \\
STm & stainless steel, clad & 30.0 & 1.0 & 2.25 & 1.00 \\
\hline \hline
\end{tabular}




\section{Total fixed capital cost for production processes}

Table 17. Total fixed capital cost estimation for the methanol plant including the subsystems of CC, DT and SYN (with MCP1 listed separately) at the baseline size. The ratio factors are selected for fluid processing plant and obtained from Ref. [49].

\begin{tabular}{llllll}
\hline \hline \multirow{2}{*}{ Items } & \multirow{2}{*}{ Ratio factor } & \multicolumn{5}{c}{ Subsystem cost $(\mathrm{M} \$)$} \\
\cline { 3 - 6 } & & $\mathrm{CC}$ & $\mathrm{DT}$ & $\mathrm{MCP} 1$ & $\mathrm{SYN}$ \\
\hline Purchased equipment cost & 1.00 & 52.58 & 14.97 & 5.31 & 57.34 \\
Installation cost & 0.47 & 24.71 & 7.04 & 2.50 & 26.95 \\
Instrumentation and controls & 0.36 & 18.93 & 5.39 & 1.91 & 20.64 \\
Piping & 0.68 & 35.75 & 10.18 & 3.61 & 38.99 \\
Electrical systems & 0.11 & 5.78 & 1.65 & 0.58 & 6.30 \\
Building and services & 0.18 & 9.46 & 2.70 & 0.96 & 10.32 \\
Yard improvements & 0.10 & 5.26 & 1.50 & 0.53 & 5.73 \\
Service facilities & 0.70 & 36.80 & 10.48 & 3.72 & 40.14 \\
Total direct cost & & 189.27 & 53.91 & 19.11 & 206.43 \\
& & & & & \\
Engineering and supervision & 0.33 & 17.35 & 4.94 & 1.75 & 18.92 \\
Construction expenses & 0.41 & 21.56 & 6.14 & 2.18 & 23.51 \\
Legal expenses & 0.04 & 2.10 & 0.60 & 0.21 & 2.29 \\
Contractor's fee & 0.22 & 11.56 & 3.29 & 1.17 & 12.62 \\
Contingency & 0.44 & 23.13 & 6.59 & 2.33 & 25.23 \\
Total indirect cost & & 75.71 & 21.56 & 7.65 & 82.57 \\
TFCC & & & & & \\
\hline \hline
\end{tabular}




\section{Raw materials and technology costs}

Table 18. Raw material and process utility price. All costs are converted to US $\$$ based on $1 €=1.14 \$$. Flue gas is assumed to be free of charge.

\begin{tabular}{lllc}
\hline \hline & Price & Unit & Source \\
\hline Flue gas & 0 & $\$ /$ tonne & {$[21]$} \\
Process water & 0.019 & $\$ /$ tonne & {$[50]$} \\
Cooling water & 0.818 & $\$ /$ MWh & {$[18]$} \\
\hline
\end{tabular}

Table 19. Technology costs used for the base case scenario. All costs are converted to US dollar based on $1 €=1.14 \$$.

\begin{tabular}{llllll}
\hline \hline & CapEx (power) & CapEx (mass) & CapEx (energy) & OpEx & \\
& $\$ / \mathrm{kW}$ & $\$ /$ tonne & $\$ / \mathrm{MWh}$ & $\$ / \mathrm{kW}$ & Source \\
\hline Inland wind & $1,473^{a}$ & - & - & - & {$[51]$} \\
Solar PV & $995^{a}$ & - & - & - & {$[51]$} \\
Electrolyser & $600^{b}$ & - & - & - & {$[52]$} \\
SOFC & $194^{c}$ & - & - & - & {$[53]$} \\
$\mathrm{H}_{2}$ storage & - & $751,700^{d}$ & - & - & {$[31]$} \\
Heat storage $^{e}$ & - & - & 25 & 40 & {$[54]$} \\
Gas turbine & $240^{f}$ & - & - & - & {$[55]$} \\
\hline \hline
\end{tabular}

${ }^{a}$ This indicates the weighted averages of total installed cost.

${ }^{b}$ This is estimated based on alkaline electrolysers at $1 \mathrm{~atm}$.

${ }^{c}$ This indicates the stack cost estimated based on $100 \mathrm{~kW}$ and 1,000 systems per year.

${ }^{d}$ CapEx of $\mathrm{H}_{2}$ storage includes steel tanks and compressors.

$e$ A lower bound is adopted from the source due to its moderate operating conditions.

$f$ This is adopted based on large simple cycle case. 
Table 20. Conservative technology costs. All costs are converted to US dollar based on $1 €=1.14 \$$.

\begin{tabular}{llllc}
\hline \hline & CapEx & Unit & Year & Source \\
\hline Inland wind & $2,450^{a}$ & $\$ / \mathrm{kW}$ & 2019 & {$[51]$} \\
Solar PV & $2,400^{a}$ & $\$ / \mathrm{kW}$ & 2019 & {$[51]$} \\
Electrolyser & 1,064 & $\$ / \mathrm{kW}$ & 2020 & {$[56]$} \\
SOFC & $1,039^{b}$ & $\$ / \mathrm{kW}$ & 2015 & {$[53]$} \\
\hline \hline
\end{tabular}

a This indicates the $95^{\text {th }}$ percentile of the source.

${ }^{b}$ This indicates the stack cost estimated based on $10 \mathrm{~kW}$ and 100 systems per year.

Table 21. Progressive technology costs. All costs are converted to US dollar based on $1 €$ $=1.14 \$$.

\begin{tabular}{llllc}
\hline \hline & CapEx & Unit & Year & Source \\
\hline Inland wind & $1,100^{a}$ & $\$ / \mathrm{kW}$ & 2019 & {$[51]$} \\
Solar PV & $750^{a}$ & $\$ / \mathrm{kW}$ & 2019 & {$[51]$} \\
Electrolyser & 414 & $\$ / \mathrm{kW}$ & 2019 & {$[17]$} \\
SOFC & $166^{b}$ & $\$ / \mathrm{kW}$ & 2015 & {$[53]$} \\
\hline \hline
\end{tabular}

${ }^{a}$ This indicates the $5^{\text {th }}$ percentile of the source.

${ }^{b}$ This indicates the stack cost estimated based on $250 \mathrm{~kW}$ and 50,000 systems per year. 


\section{Auxiliary results}

Table 22. Size of individual units for the $100 \%$ renewable operations in the two locations.

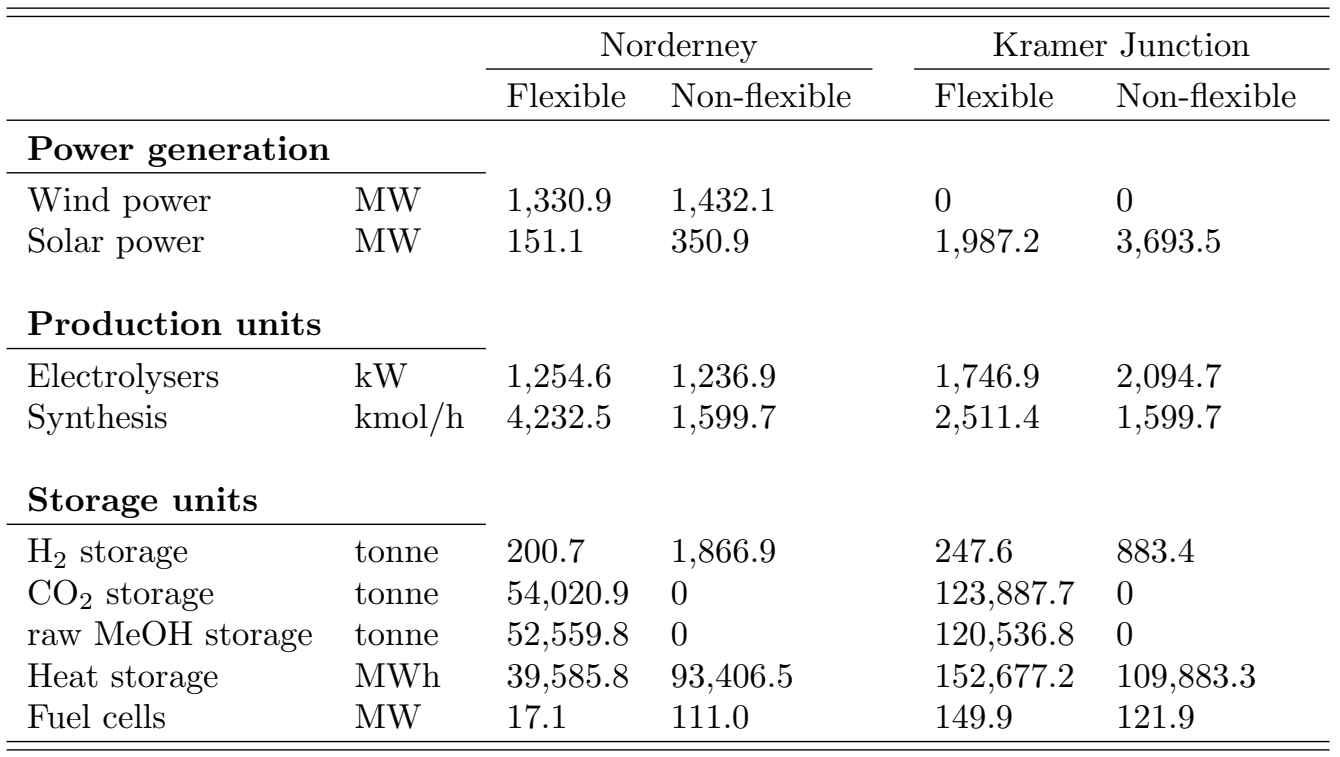

Table 23. Key variables for Norderney at selected ramp limits (for both ramp-up and -down). Ramp limit is measured in terms of fraction of rated capacity.

\begin{tabular}{llllll}
\hline \hline $\begin{array}{l}\text { Ramp limit } \\
\%\end{array}$ & $\begin{array}{l}\text { LCOMeOH } \\
\text { \$/tonne }\end{array}$ & $\begin{array}{l}\dot{\xi} \\
\mathrm{kmol} / \mathrm{h}\end{array}$ & $\begin{array}{l}L_{\max }^{\mathrm{STh}} \\
\text { tonne }\end{array}$ & $\begin{array}{l}L_{\max }^{\mathrm{STm}} \\
\text { tonne }\end{array}$ & $\begin{array}{l}f_{\mathrm{W}} \\
\%\end{array}$ \\
\hline 0.01 & $1,201.9$ & 1,884 & 1,248 & 28,041 & 80.6 \\
0.1 & $1,136.1$ & 2,527 & 986 & 37,859 & 82.1 \\
1 & $1,017.3$ & 4,303 & 354 & 50,476 & 93.7 \\
5 & 984.6 & 4,249 & 200 & 52,934 & 95.1 \\
10 & 983.2 & 4,234 & 200 & 52,596 & 95.4 \\
20 & 982.4 & 4,229 & 201 & 52,520 & 95.5 \\
Unlimited & 982.2 & 4,233 & 201 & 52,560 & 95.5 \\
\hline \hline
\end{tabular}




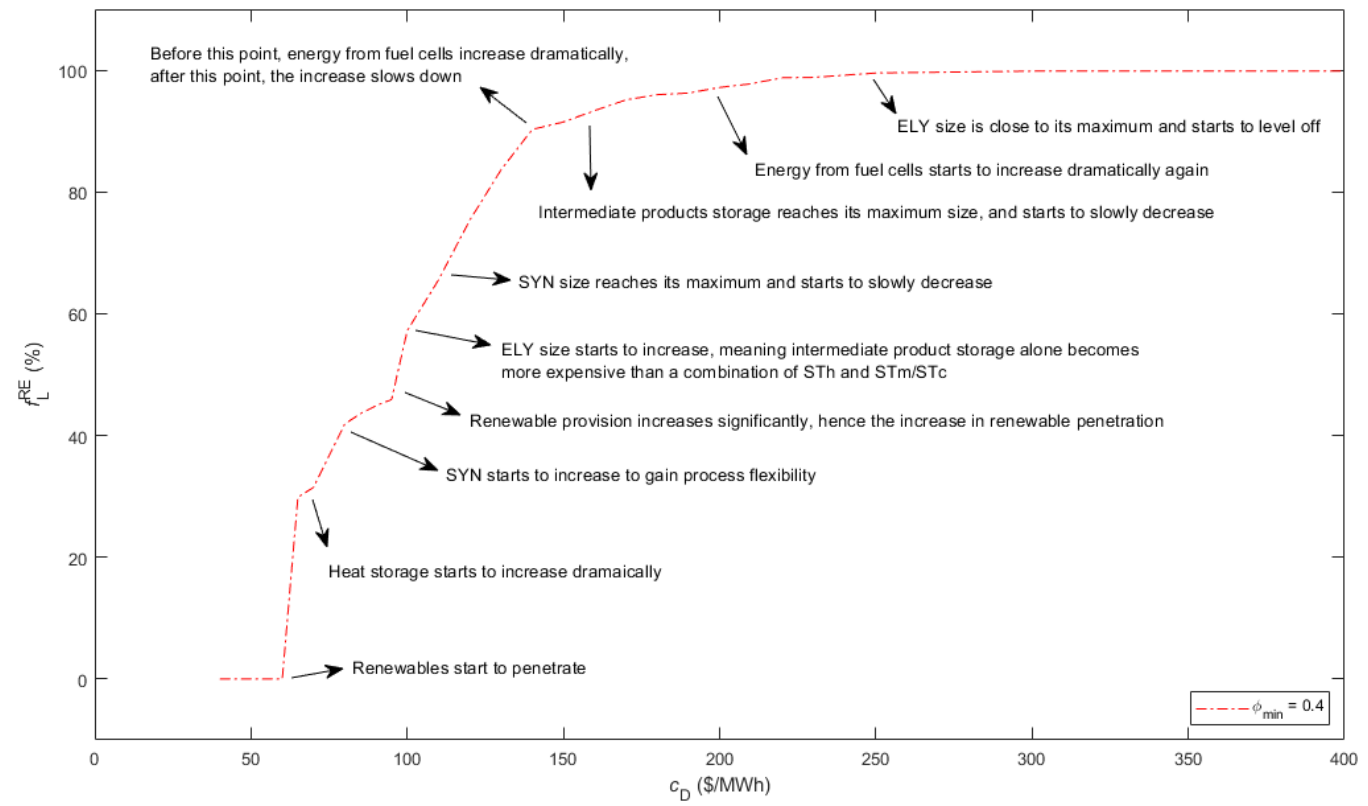

Figure 12. Explanation of the renewable penetration behaviour from a mechanistic viewpoint using the case of $\phi_{\min }=0.4$ as an example.

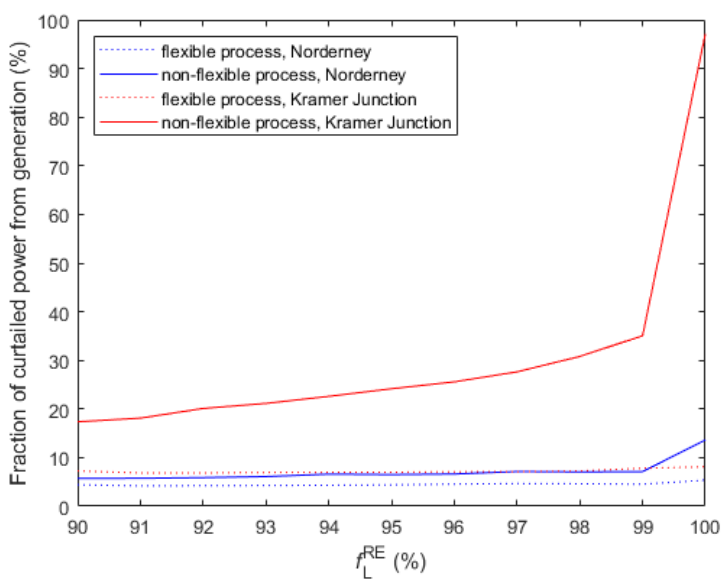

Figure 13. Fraction of the curtailed renewable power $P_{\text {out }}$ plotted against $f_{\mathrm{L}}^{\mathrm{RE}}$. 


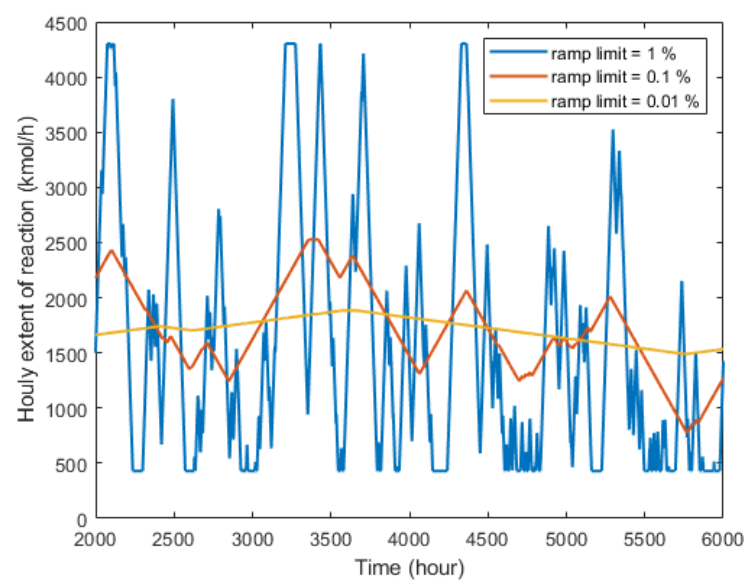

Figure 14. Example of reactor operation for selected ramp limits. Ramp limit is measured in terms of fraction of rated capacity

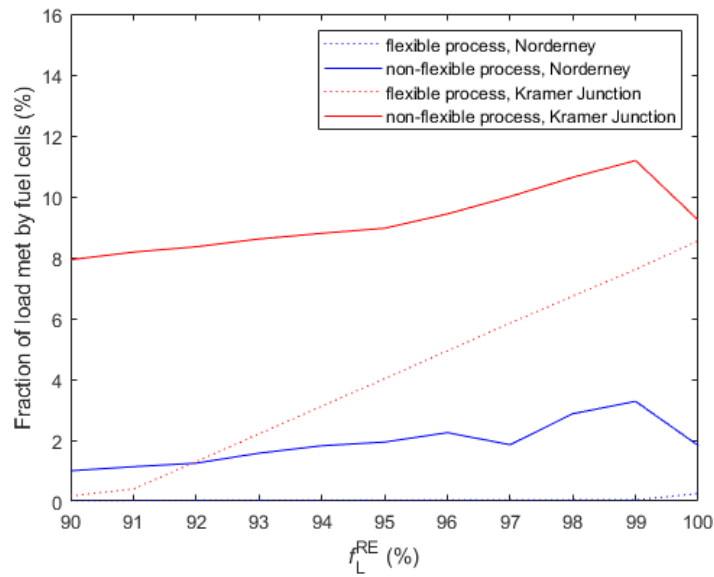

Figure 15. Fraction of the load met by $E_{\mathrm{ST}}$ plotted against $f_{\mathrm{L}}^{\mathrm{RE}}$. 

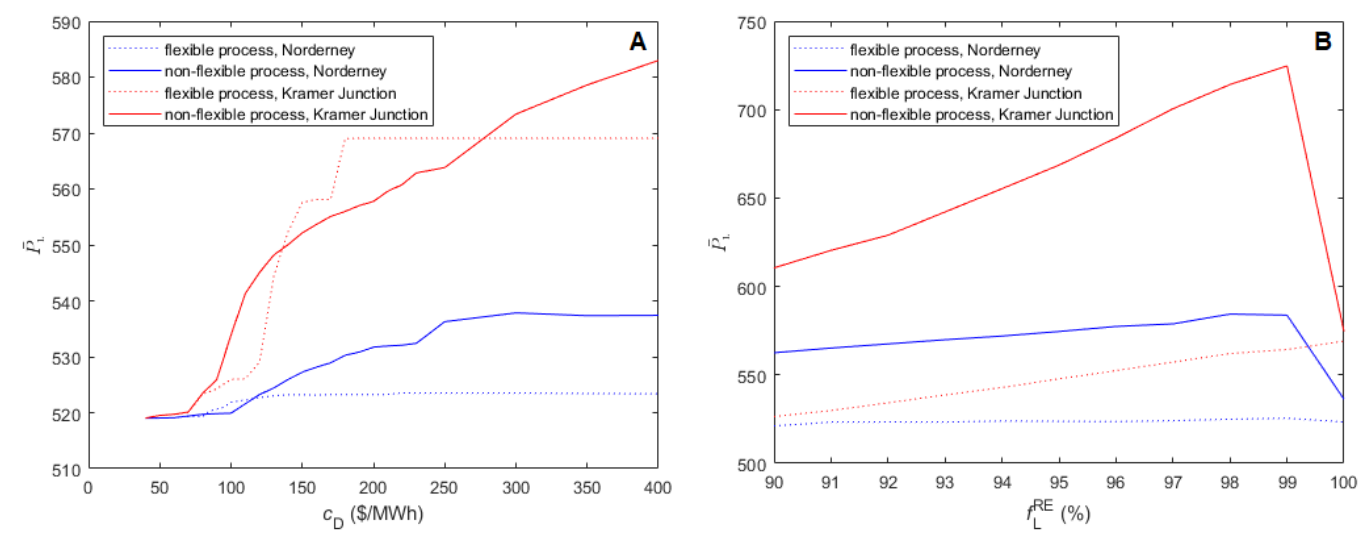

Figure 16. Average load of the methanol production process $\left(\overline{P_{\mathrm{L}}}\right)$ plotted against $(\mathrm{A}) c_{\mathrm{D}}$ and (B) $f_{\mathrm{L}}^{\mathrm{RE}}$ for the optimal operations.
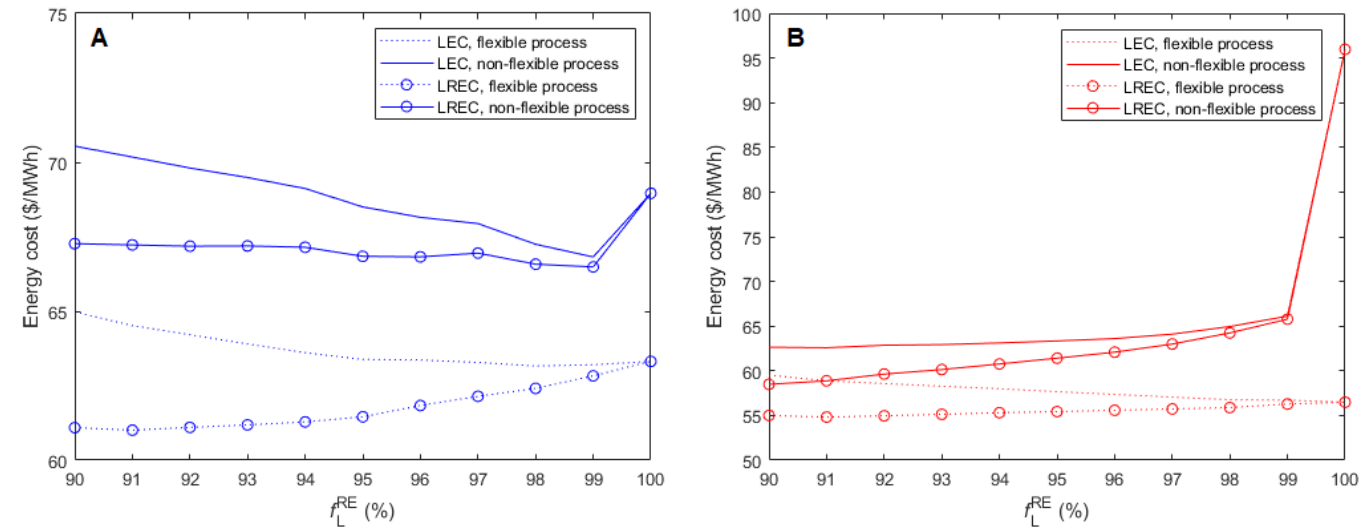

Figure 17. Levelised energy cost (LEC) and levelised renewable energy cost (LREC) plotted against $f_{\mathrm{L}}^{\mathrm{RE}}$ for the optimal operations in (A) Norderney and (B) Kramer Junction. 